\title{
Joint procurement and pricing of fresh produce for multiple retailers with a quantity discount contract
}

\author{
Qi Zhenga, Li Zhoub, Tijun Fanc,*, Petros Ieromonachoub \\ a School of Management, Shanghai University of Engineering Science, Shanghai, China \\ ${ }^{b}$ Faulty of Business, University of Greenwich, London, UK \\ c School of Business, East China University of Science and Technology, Shanghai, China
}

\begin{abstract}
This study considers a fresh produce supply chain consisting of one supplier and multiple retailers with a quantity discount contract in two scenarios-independent procurement and joint procurement. The supplier's optimal pricing decision and the retailers' optimal procurement decisions under the quantity discount contract are investigated. Furthermore, the impact of the deterioration rate on the profit of supply chains is examined. The results show that joint procurement is more profitable than independent procurement and guarantees a win-win outcome. More importantly, retailers will be motivated to form a grand coalition when the total profit can be rationally allocated among them.
\end{abstract}

Key words: Fresh produce; Supply chain; Joint procurement; Contract; Coordination

\section{Introduction}

In 2013, the Chinese government proposed the Belt and Road Initiative (BRI) to boost regional cooperation and called for the establishment of a new regional cooperation model. The BRI aims to start a new era of economic growth along the breadth and length of Asia, Europe and Africa (Liu et al., 2018). This strategy connects China with its neighbors in Asia and more than 60 other countries. The BRI has brought a great deal of business opportunities to the countries along the BRI corridors, creating a strategic position in the globalization.

The countries linked through the BRI hold abundant fresh produce resources, and China has an enormous market demand for these products. Therefore, the supply-demand relationship of

\footnotetext{
* Corresponding author: School of Business, East China University of Science and Technology, Shanghai, China

E-mail addresses: tifan@ecust.edu.cn (T. Fan).
} 
fresh produce can promote cooperation between these countries and advance the implementation of mutually beneficial international policies, which will bring new opportunities for the fresh produce supply chain (FPSC). The countries joining the BRI have accelerated the construction of transport infrastructures to improve the efficiency of the FPSC. For instance, tropical fruits can be transported along the BRI from Southeast Asia to China by China Cargo Airlines or China Railway Express.

In the BRI context, fresh produce is transported from Southeast Asia to China. In FPSC management, one of the greatest challenges is to maintain product freshness. In reality, to reduce losses caused by deterioration, retailers may cooperatively procure fresh produce to improve their own profits. For example, Malaysia, one country along the BRI, supplies tropical fruits to many different supermarkets in China, and most of these retailers have joined together to procure products to receive a lower selling price from the supplier. This collective action on the part of these retailers constitutes a joint procurement strategy, in which the retailers have formed a grand coalition and obtained a quantity discount contract.

However, the question is whether this joint procurement strategy is better than independent procurement under the BRI. Different from Nie et al. (2015), by mainly focusing on joint procurement to coordinate the supply chain, our research not only studies joint procurement among retailers but also considers the impact of the deterioration rate on FPSC operations. Generally, in this paper, we investigate the following two procurement strategies: (1) one strategy in which each retailer procures fresh produce from a supplier individually and (2) another in which retailers form a grand coalition to place an aggregated order with a supplier, which may involve a coordination cost. The objective is to maximize the total profits in an FPSC by considering two unique variables of an FPSC, quantity discounts and deterioration rates.

The study focuses on a two-echelon FPSC consisting of one supplier and multiple retailers. By applying game theory, we develop mathematical models under independent procurement and joint procurement. To maximize profit, there are two variables to determine: the supplier's selling price and the ordering cycle for both the supplier and the retailers. We also investigate how FPSC coordination and a win-win outcome can be achieved between the supplier and the retailers.

The remainder of this paper is organized as follows. In Section 2, we review the related 
literature and position our work before describing the model and assumptions in Section 3. In Section 4, we study the quantity discount and coordination of the FPSC under the independent procurement strategy. In Section 5, we present our investigation of the quantity discount in the FPSC under the joint procurement strategy. In Section 6, we present an extended model under joint procurement and consider the coordination costs. In Section 7, we use numerical examples to illustrate the model before drawing our conclusions in Section 8.

\section{Literature review}

In this section, we review the literature spanning four streams based on our modeling approach. First, we discuss supply chain management under the BRI. Second, we discuss FPSC issues in operations management. This review primarily covers recent analytical work addressing various issues related to inventory management, pricing, and ordering strategies. Third, we discuss the work related to contracting coordination in the supply chain stream. Fourth, we discuss different supply chain structures as applied to operations management.

In recent years, there has been a growing trend to research supply chain management under the BRI. Liu et al. (2018) explored the impacts of cost-sharing contract on the key decisions for a logistics service supply chain with mass customization. Zeng et al. (2018) proposed a modified gravity prediction model to calculate the changes in shipping networks under the BRI. Sheu and Kundu (2018) developed a multi-methodological approach to address the dynamic challenges of international logistic network reconfiguration caused by the BRI. Jiang et al. (2018) discussed an integrated fresh produce scheduling problem that combined harvest and distribution simultaneously to reduce processing time and quality decay. It appears most of the previous research focused on the logistics service and transportation network. There has been no consideration for the contracting coordination with joint procurement of FPSC under the BRI.

In the past two decades, there have been a large number of quantitative studies on FPSCs. These studies have mainly focused on inventory management, pricing, and ordering strategies. Wang and $\mathrm{Li}$ (2012) argued that although predicting the quality of perishable products is difficult, it is possible to develop a pricing method to maximize profit based on more accurate information about product quality. Tat et al. (2015) developed an economic order quantity model for 
non-instantaneous deteriorating items with and without shortages to investigate the performance of a vendor-managed inventory system. Hou et al. (2017) introduced an ordering strategy for fresh produce with back storage at a wholesale market. Some studies have considered the three factors in combination. For instance, Herbon et al. (2014) examined a replenishment policy in regular time for perishable products and developed a dynamic pricing strategy to attract more consumers and generate greater profit. Chen et al. (2014) analyzed the issue of joint pricing and inventory control for perishable products with fixed lifetimes over a finite horizon. Li et al. (2015) considered strategies of inventory control and joint dynamic pricing for perishable products in a stochastic inventory system. Sainathan (2013) focused on perishable products with two-period shelf lives in an infinite horizon and derived optimal pricing decisions and ordering strategies. However, none of these studies has considered the ways in which FPSCs can be coordinated with a contract.

The application of contracts for supply chain coordination has attracted attention from practitioners and scholars. Contract management and coordination are crucial in FPSCs. Importantly, supply chain members usually have different coordination strategies, and contracts are an alternative strategy to coordinate supply chains. Cai et al. (2013) designed an incentive scheme to coordinate an FPSC with one supplier and one retailer; this scheme examined whether an incentive contract could remove the double marginalization that exists in supply chains and encourage partners to act in a coordinated manner. Duan et al. (2010) investigated a "one vendor and one buyer" supply chain for perishable products; they proposed a model to analyze the benefits of coordinating supply chains using a quantity discount strategy and how to achieve an optimized win-win outcome. Zhang et al. (2015) developed a cooperative investment and revenue-sharing contract to coordinate all parties involved in an FPSC; all players jointly invested in technology to reduce deterioration. Wang and Chen (2017) studied an FPSC consisting of a supplier and a retailer, they examined the option pricing strategy in the newsvendor framework with wholesale price and call option portfolio contracts. In addition, some authors have used different approaches to coordinate inventory systems (Taleizadeh \& Noori-daryan, 2015; Taleizadeh et al., 2016; Taleizadeh et al., 2014; Taleizadeh et al., 2015). The above papers mainly focused on the coordination mechanisms in an FPSC with one supplier and one retailer. They did not consider how to coordinate a supply chain with multiple retailers. 
There is little research on coordinating an FPSC consisting of one supplier and multiple retailers or multiple retailers and one supplier through a contract. Zhang et al. (2012) analyzed how to coordinate a supply chain with one manufacturer and two competing retailers under demand disruptions. Cao et al. (2013) considered a supply chain with one supplier and multiple retailers that competed in quantity; they researched how production costs and demand disruptions impact a revenue-sharing contract. Chen (2012) explored a coordination mechanism and various procurement policies for a supply chain with multiple suppliers and one manufacturer in the electronics market. Mohebbi and Li (2015) developed a mathematical model for a coalition of multiple suppliers based on game theory and improved individual profit in the network. Lim et al. (2015) showed how to coordinate a supply chain with one retailer and multiple suppliers using consignment contracts when considering revenue sharing. Taleizadeh et al. (2016) introduced different composite coordinating strategies to enhance the coordination of supply chains, where each supply chain was composed of one manufacturer and a group of noncompeting retailers. Ye et al. (2016) conducted a systematic analysis of the efficiency of unilateral or bilateral horizontal competitive reverse supply chains with quality-dependent price-only contracts. Noori-daryan et al. (2017) analyzed the optimal pricing and replenishment decisions of a supply chain consisting of a single manufacturer and multiple retailers, where a composite contract combines quantity and freight discounts and a composite incentive contract is incorporated into the model. However, the models of these studies have not considered the characteristics of fresh produce and quantity discount contracts.

To address the joint procurement issue, we develop a mathematical model of joint procurement for a coalition of retailers, and analytical results are obtained by comparing the cases of independent procurement and joint procurement. Akcay et al. (2010) used an algorithm of multinomial time to investigate the optimal joint dynamic pricing of multiple perishable products when considering strategic consumers. Gallego and Hu (2014) presented a joint pricing approach for competitive products in a special market environment with perishable products consisting of substitutable and complementary products to derive optimal pricing solutions. Taleizadeh et al. (2017) studied a joint pricing and alliance selection decision-making problem in a retailer-led supply chain. Our model, however, combines critical parameters involved in the joint procurement 
of multiple retailers and one supplier with a quantity discount contract.

Table 1 summarizes the literature and notes the differences compared to our research. The above review suggests that (1) the coordination of FPSCs with one supplier and multiple retailers has been minimally studied; (2) studies considering a joint procurement strategy for retailers are rare; and (3) the profit allocation of retailers under joint procurement in FPSCs is infrequently examined. The main difference between our paper and the above literature is that we focus on developing a quantity discount contract to coordinate an FPSC consisting of one supplier and multiple retailers. We do so by comparing two scenarios, independent procurement and joint procurement, to create a pricing strategy and to investigate the profit allocation among the retailers. 
Table 1 Summary of the relevant literature

\begin{tabular}{|c|c|c|c|c|c|c|c|c|}
\hline \multirow{2}{*}{ Authors } & \multicolumn{3}{|c|}{ Decision policy } & \multicolumn{3}{|c|}{ Supply chain structure } & \multirow{2}{*}{ Deterioration } & \multirow{2}{*}{ Focus } \\
\hline & Pricing & Ordering & Inventory & $1-1$ & $1-\mathrm{N}$ & $\mathrm{N}-1$ & & \\
\hline Wang and Li (2012) & $\sqrt{ }$ & & & $\sqrt{ }$ & & & $\sqrt{ }$ & Optimizing decisions \\
\hline Tat et al. (2015) & & & $\sqrt{ }$ & $\sqrt{ }$ & & & $\sqrt{ }$ & Optimizing decisions \\
\hline Hou et al. (2017) & & $\sqrt{ }$ & & $\sqrt{ }$ & & & $\sqrt{ }$ & Optimizing decisions \\
\hline Herbon et al. (2014) & $\sqrt{ }$ & & & & & & $\sqrt{ }$ & Optimizing decisions \\
\hline Chen et al. (2014) & $\sqrt{ }$ & & $\sqrt{ }$ & & & & $\sqrt{ }$ & Optimizing decisions \\
\hline Sainathan (2013) & $\sqrt{ }$ & $\sqrt{ }$ & & & & & $\sqrt{ }$ & Optimizing decisions \\
\hline Cai et al. (2013) & & & & $\sqrt{ }$ & & & & Contracting coordination (incentive contract) \\
\hline Duan et al. (2010) & & & & $\sqrt{ }$ & & & $\sqrt{ }$ & Contracting coordination (quantity discount contract) \\
\hline Zhang et al. (2015) & & & & $\sqrt{ }$ & & & & Contracting coordination (revenue-sharing contract) \\
\hline Wang and Chen (2017) & $\sqrt{ }$ & & & $\sqrt{ }$ & & & & Contracting coordination (option contract) \\
\hline Zhang et al. (2012) & & & & & $\sqrt{ }$ & & & Contracting coordination (revenue-sharing contract) \\
\hline Cao et al. (2013) & & & & & $\sqrt{ }$ & & & Contracting coordination (revenue-sharing contract) \\
\hline Chen (2012) & & & & & & $\sqrt{ }$ & & Optimizing decisions \\
\hline Mohebbi and Li (2015) & & & & & & $\sqrt{ }$ & & Optimizing decisions \\
\hline Taleizadeh et al. (2016) & & & & & & $\sqrt{ }$ & & Optimizing decisions \\
\hline Lim et al. (2015) & & & & & & $\sqrt{ }$ & & Optimizing decisions \\
\hline Noori-daryan et al. (2017) & $\sqrt{ }$ & & & & $\sqrt{ }$ & & & Contracting coordination (composite incentive contract) \\
\hline Akcay et al. (2010) & $\sqrt{ }$ & & & & & & $\sqrt{ }$ & Optimizing decisions \\
\hline Gallego and $\mathrm{Hu}(2014)$ & $\sqrt{ }$ & & & & & & $\sqrt{ }$ & Optimizing decisions \\
\hline Taleizadeh et al. (2017) & $\sqrt{ }$ & & & $\sqrt{ }$ & & & & Optimizing decisions \\
\hline This paper & $\sqrt{ }$ & & & & $\sqrt{ }$ & & $\sqrt{ }$ & $\begin{array}{c}\text { Contracting coordination (quantity discount contract) \& profit } \\
\text { allocation }\end{array}$ \\
\hline
\end{tabular}




\section{Problem description}

We consider a two-tier supply chain composed of one supplier and many retailers. In this chain, the retailers purchase fresh produce from the supplier. The retailers determine the ordering cycle. When they sign the quantity discount contract, the supplier requests that the retailers change their current order size and offers them compensation via a quantity discount at a low selling price. From the retailers' perspective, they negotiate jointly, form a coalition to gain more profit and rationally allocate the total profit of their coalition. When the selling season begins, the retailers have no opportunity to replenish their inventory. Figure 1 demonstrates the research framework for multiple retailers in an FPSC.

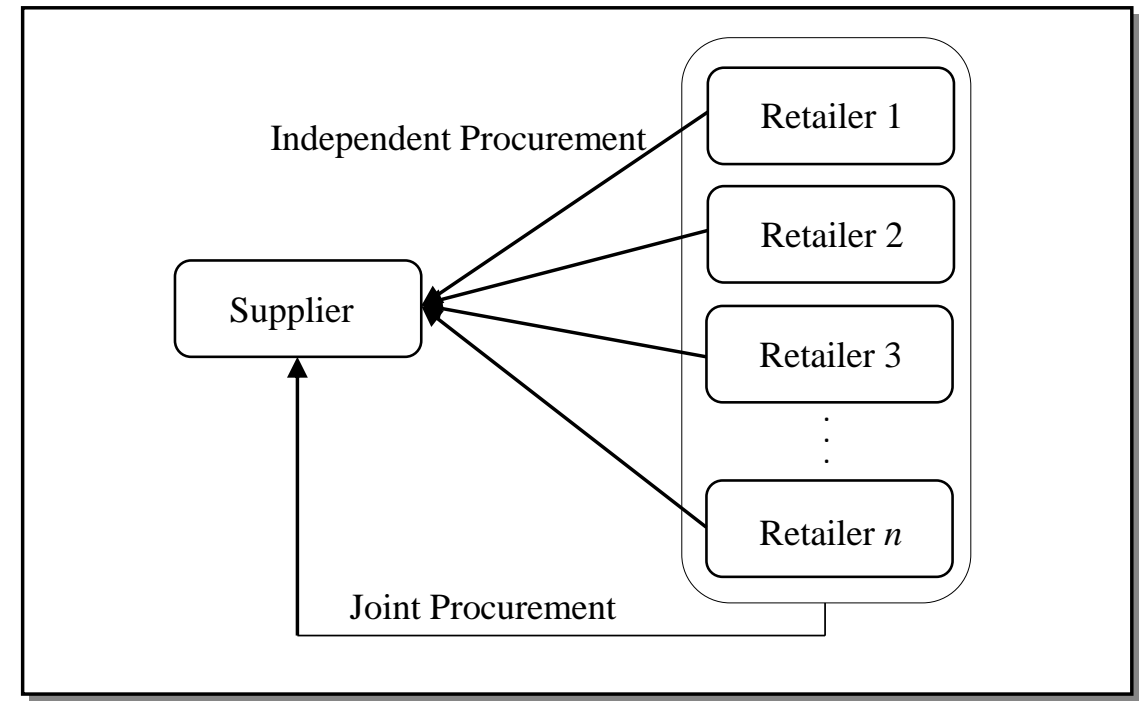

Figure 1 Research framework for multiple retailers in an FPSC

In this paper, the supply chain consists of one supplier and $n$ different retailers. Let $N=\{1,2, \mathrm{~L}, n\}$, which is a set of retailers in the game, where $n$ is the number of retailers in the coalition. To simplify the mathematical model without losing generality, we assume the following:

- The supplier acts as the leader, and the retailers are the followers.

- The salvage value of unsold products at the end of the sale period is zero.

- Demand is constant.

- Stock-out is not allowed. 
- The supplier has the ability to provide fresh produce to the retailers immediately.

We develop a mathematical model for an FPSC consisting of one supplier and multiple retailers under different conditions. According to Tavakoli and Taleizadeh (2017), the inventory level at time $t$ decreases due to demand and deterioration. Therefore, according to this description, the inventory changes with respect to time, $I(t)$, are satisfied by the following equation:

$$
\frac{d I_{i}(t)}{d t}=-\theta I_{i}(t)-D_{i}, \quad 0 \leq t \leq T_{i}
$$

This equation has a boundary condition of $I_{i}\left(T_{i}\right)=0$, where $I(t)$ is the inventory level of products at time $t, T_{i}$ is the ordering cycle length of retailer $i, D_{i}$ is the demand rate of retailer $i$ per unit time, and $\theta$ is the deterioration rate of fresh produce. For the first and second differential equations, the solution of Eq. (1) is as follows:

$$
I_{i}(t)=\frac{D_{i}}{\theta}\left(e^{\theta\left(T_{i}-t\right)}-1\right), 0 \leq t \leq T_{i}
$$

The main objective of this study is to gain new insights into effective joint procurement management such that the total cost is minimized and the total profit is maximized simultaneously. Some notations and parameters are as follows:

$K_{s}$ : the fixed ordering cost of the supplier;

$K_{r}$ : the fixed ordering cost of the retailers;

$D_{i}$ : the demand rate of retailer $i$ per unit time;

$h_{i}$ : the inventory holding cost per unit;

$I(t)$ : the inventory level of products at time $t$;

$\theta$ : the deterioration rate of fresh produce;

$p$ : the selling price that the retailers charge consumers per unit;

$c$ : the supplier's production cost per unit;

$Q_{i}$ : the ordering quantity of retailer $i$;

$x_{i}(\alpha)$ : the profit allocation to retailer $i$;

$\pi_{s}$ : the profit of the supplier; 
$\pi_{r i}$ : the profit of retailer $i$;

$\alpha$ : the selling price that the supplier charges the retailers per unit; and

$T_{i}$ : the ordering cycle

\section{Coordination of the FPSC under independent procurement}

In this section, we examine the coordination of an FPSC with and without a quantity discount contract under independent procurement.

\subsection{Scenario I: without a quantity discount contract}

When the supplier and each retailer act as individuals in an FPSC without a quantity discount contract, they try to maximize their own profit and ignore the interests of others.

In this situation, the ordering quantity of retailer $i$ is set to equal an initial inventory level of fresh produce (Taleizadeh et al., 2013), $Q_{i}\left(T_{D i}^{w}\right)=I_{i}(0)$. Let superscript $w$ and subscript $D$ denote the case without a quantity discount under independent procurement. Thus, the retailer's ordering quantity, denoted by $Q_{i}\left(T_{D i}^{w}\right)$, is as follows:

$$
Q_{i}\left(T_{D i}^{w}\right)=\frac{D_{i}}{\theta}\left(e^{\theta T_{D i}^{w}}-1\right)
$$

The total cost for retailer $i$ is composed of three parts: (1) the ordering cost, which is equal to $K_{r} ;(2)$ the inventory holding cost,

$$
h_{i} \int_{0}^{T_{D i}^{w}} \frac{D_{i}}{\theta}\left(e^{\theta\left(T_{D i}^{w}-t\right)}-1\right) d t=h_{i} D_{i} \frac{e^{\theta T_{D i}^{w}}-\theta T_{D i}^{w}-1}{\theta^{2}} ;
$$

and (3) the procurement cost, $\alpha_{D i}^{w} D_{i} \frac{e^{\theta T_{D i}^{w}}-1}{\theta}$.

Hence, the profit $\pi_{D r i}^{w}\left(T_{D i}^{w}\right)$ of retailer $i$ per unit of time is as follows:

$$
\pi_{D r i}^{w}\left(\alpha_{D i}^{w}, T_{D i}^{w}\right)=p_{i} D_{i}-\frac{K_{r}}{T_{D i}^{w}}-h_{i} D_{i} \frac{e^{\theta T_{D i}^{w}}-\theta T_{D i}^{w}-1}{\theta^{2} T_{D i}^{w}}-\alpha_{D i}^{w} D_{i} \frac{e^{\theta T_{D i}^{w}}-1}{\theta T_{D i}^{w}}
$$

The truncated Taylor series is used as a good approximation (Taleizadeh et al., 
2013). Utilizing the truncated Taylor series expansion for the exponential term

$$
e^{\theta T}=1+\theta T+\frac{1}{2}(\theta T)^{2}
$$

the profit of retailer $i$ per unit of time in Eq. (4) can be simplified as follows:

$$
\pi_{D r i}^{w}\left(\alpha_{D i}^{w}, T_{D i}^{w}\right)=\left(p_{i}-\alpha_{D i}^{w}\right) D_{i}-\frac{K_{r}}{T_{D i}^{w}}-\frac{T_{D i}^{w}}{2}\left(h_{i}+\alpha_{D i}^{w} \theta\right) D_{i} .
$$

We take the supplier's selling price for retailer $\alpha_{D i}^{w}$ as a benchmark for an FPSC without a contract. In the following sections, we set $\alpha_{D i}^{w}$ as a parameter for the optimal supplier's selling price for retailers with a quantity discount contract. Now, consider the situation involving the coordination of the FPSC without a contract under independent procurement. For a given $\alpha_{D i}^{w}$, taking the first derivative of Eq. (6) with respect to the ordering cycle $T_{D i}^{w}$, we set it equal to 0 ; therefore, $\frac{d \pi_{D r i}^{w}\left(\alpha_{D i}^{w}, T_{D i}^{w}\right)}{d T_{D i}^{w}}=\frac{K_{r}}{\left(T_{D i}^{w}\right)^{2}}-\frac{\left(h_{i}+\alpha_{D i}^{w} \theta\right) D_{i}}{2}=0$. Taking the second derivative of Eq. (6) with respect to $T_{D i}^{w}$, we have $\frac{d^{2} \pi_{D r i}^{w}\left(\alpha_{D i}^{w}, T_{D i}^{w}\right)}{d\left(T_{D i}^{w}\right)^{2}}=-\frac{2 K_{r}}{\left(T_{D i}^{w}\right)^{3}}<0$, which proves that the retailer's profit function $\pi_{D r i}\left(\alpha_{D i}^{w}, T_{D i}^{w}\right)$ is concave to $T_{D i}^{w}$. Therefore, we find that the optimal ordering cycle is as follows:

$$
T_{D i}^{w *}=\sqrt{\frac{2 K_{r}}{\left(h_{i}+\alpha_{D i}^{w} \theta\right) D_{i}}}
$$

Substituting $T_{D i}^{w *}$ into Eq. (6), we obtain the retailer's optimal profit in the decentralized FPSC as follows:

$$
\pi_{D r i}^{w}\left(\alpha_{D i}^{w}, T_{D i}^{w *}\right)=\left(p_{i}-\alpha_{D i}^{w}\right) D_{i}-\sqrt{2 K_{r}\left(h_{i}+\alpha_{D i}^{w} \theta\right) D_{i}} .
$$

Therefore, the supplier's optimal profit is: 


$$
\pi_{D s}^{w}=\sum_{i=1}^{n}\left(\alpha_{D i}^{w} D_{i}-c D_{i}-\frac{K_{s}}{T_{D i}^{w^{*}}}\right)
$$

In the following section, we determine whether an FPSC can be coordinated by a quantity discount contract under independent procurement.

\subsection{Scenario II: with a quantity discount contract}

This section addresses FPSC coordination with a quantity discount contract. We are interested in whether the FPSC can be coordinated in this scenario and under what conditions. The supplier's objective is to increase profit by enticing the retailers to order more fresh produce. Under the quantity discount strategy, the supplier requests that the retailers change their current order size and offers them compensation via a quantity discount at a low selling price, $\alpha_{D i}^{c w}$. Let superscript $c w$ and subscript $D$ denote the case of a quantity discount under independent procurement.

In this paper, we assume that the supplier is the supply chain leader and that the objective is to maximize the supplier's profit. Based on the above discussion regarding system operation, the problem can be modeled in terms of two decision variables, $\left(\alpha_{D i}^{c w}, T_{D i}^{c w}\right)$. Therefore, the optimization problem of FPSC coordination under a quantity discount contract can be formulated as follows:

$$
\begin{gathered}
\max \pi_{D s}^{c w}\left(\alpha_{D i}^{c w}, T_{D i}^{c w}\right)=\sum_{i=1}^{n}\left(\alpha_{D i}^{c w}-c\right) D_{i}-\frac{K_{s}}{T_{D i}^{c w}} \\
\text { s.t. } \pi_{D r i}^{c w}\left(\alpha_{D i}^{c w}, T_{D i}^{c w}\right)=\left(p_{i}-\alpha_{D i}^{c w}\right) D_{i}-\frac{K_{r}}{T_{D i}^{c w}}-\frac{T_{D i}^{c w}}{2}\left(h_{i}+\alpha_{D i}^{c w} \theta\right) D_{i} \geq \pi_{D r i}^{w}\left(\alpha_{D i}^{w}, T_{D i}^{w *}\right)
\end{gathered}
$$

Eq. (11) indicates that the retailers accept the contract only if their individual profit is no less than that in the case without a quantity discount contract (Scenario I). Here, $\alpha_{D i}^{c w}$ is an endogenous variable, while $\alpha_{D i}^{w}$ is an exogenously given variable.

By solving the constraint condition, we have the supplier's optimal selling price that it charges the retailers: 


$$
\alpha_{D i}^{c w *}=\left(\alpha_{D i}^{w}+\sqrt{\frac{2 K_{r}\left(h_{i}+\alpha_{D i}^{w} \theta\right)}{D_{i}}}-\frac{K_{r}}{D_{i} T_{D i}^{c w}}-\frac{T_{D i}^{c w}}{2} h_{i}\right) /\left(1+\frac{T_{D i}^{c w}}{2} \theta\right)
$$

Eq. (12) shows that the supplier's selling price $\alpha_{D i}^{c w}$ under the quantity discount contract has a certain relationship with the selling price $\alpha_{D i}^{w}$ without the contract.

Substituting Eq. (12) into Eq. (10), we obtain the optimal profit of the supplier as follows:

$$
\pi_{D s}^{c w^{*}}\left(T_{D i}^{c w}\right)=\sum_{i=1}^{n} \frac{\alpha_{D i}^{w} D_{i}+\sqrt{2 K_{r} D_{i}\left(h_{i}+\alpha_{D i}^{w} \theta\right)}-\frac{K_{r}}{T_{D i}^{c w}}-\frac{D_{i} T_{D i}^{c w}}{2} h_{i}}{1+\frac{T_{D i}^{c w}}{2} \theta}-\frac{K_{s}}{T_{D i}^{c w}}-\sum_{i=1}^{n} c D_{i}
$$

Taking the first derivative of Eq. (13) with respect to the ordering cycle $T_{D i}^{c w}$, we obtain the following equation:

$$
\frac{d \pi_{D s}^{c w *}\left(T_{D i}^{c w}\right)}{d T_{D i}^{c w}}=\frac{-A\left(T_{D i}^{c w}\right)^{2}+\left(K_{s}+n K_{r}\right)+\left(K_{s}+n K_{r}\right) \theta T_{D i}^{c w}}{\left(1+\frac{T_{D i}^{c w}}{2} \theta\right)^{2}\left(T_{D i}^{c w}\right)^{2}}
$$

where $A=\sum_{i=1}^{n} \frac{D_{i} h_{i}}{2}+\frac{\theta}{2} \sum_{i=1}^{n}\left(\alpha_{D i}^{w} D_{i}+\sqrt{2 K_{r} D_{i}\left(h_{i}+\alpha_{D i}^{w} \theta\right)}\right)-\frac{K_{s} \theta^{2}}{4}$.

Solving $\frac{d \pi_{D s}^{c w *}\left(T_{D i}^{c w}\right)}{d T_{D i}^{c w}}=0$, we obtain the ordering cycle as follows:

$$
T_{D i}^{c w *}=\frac{\left(K_{s}+n K_{r}\right) \theta+\sqrt{\left(K_{s}+n K_{r}\right)^{2} \theta^{2}+4 A\left(K_{s}+n K_{r}\right)}}{2 A} .
$$

Taking the second derivative of Eq. (13) with respect to ordering cycle $T_{D i}^{c w}$, we obtain the following equation:

$$
\begin{aligned}
\frac{d^{2} \pi_{D s}^{c w *}\left(T_{D i}^{c w}\right)}{d\left(T_{D i}^{c w}\right)^{2}}= & -2 A\left(T_{D i}^{c w}\right)^{3}\left[\left(1+\frac{\theta}{2} T_{D i}^{c w}\right)^{2}+\left(1+\frac{3}{2} \theta T_{D i}^{c w}+\frac{\theta^{2}}{2}\left(T_{D i}^{c w}\right)^{2}\right)\right] \\
& -\left(K_{s}+n K_{r}\right)\left[2 T_{D i}^{c w}+4 \theta\left(T_{D i}^{c w}\right)^{2}+3 \theta^{2}\left(T_{D i}^{c w}\right)^{3}+\frac{3}{4} \theta^{3}\left(T_{D i}^{c w}\right)^{4}\right] .
\end{aligned}
$$

Eq. (15) shows that $\frac{d^{2} \pi_{D s}^{c w^{*}}\left(T_{D i}^{c w}\right)}{d\left(T_{D i}^{c w}\right)^{2}}<0$, which has a maximum value occurring at 
$T_{D i}^{c w}=T_{D i}^{c w *}$. Therefore, $T_{D i}^{c w *}$ is the optimal ordering cycle.

Proposition 1. For the independent procurement case, when the supplier's selling price $\quad \alpha_{D i}^{c w} \quad$ satisfies $\quad \alpha_{D i}^{c w}=\left\{\begin{array}{l}\alpha_{D i}^{c w *}, T_{D i}^{c w}=T_{D i}^{c w^{*}} \\ \alpha_{D i}^{w}, \text { otherwise }\end{array}, \quad\right.$ where $\alpha_{\min }^{c w *} \leq \alpha_{D i}^{c w^{*}} \leq \alpha_{\max }^{c w^{*}} \quad, \quad \alpha_{\max }^{c w^{*}}=\min _{i \in N} \alpha_{D i}^{c w^{*}}$ and $\alpha_{\text {min }}^{c w^{*}}=\sum_{i=1}^{n}\left(\alpha_{D i}^{w} D_{i}-K_{s} \sqrt{\frac{\left(h_{i}+\alpha_{D i}^{w} \theta\right) D_{i}}{2 K_{r}}}+\frac{K_{s}}{T_{D i}^{c * *}}\right) / \sum_{i=1}^{n} D_{i}$, the quantity discount contract $\left(\alpha_{D i}^{c w^{*}}, T_{D i}^{c w^{*}}\right)$ can facilitate FPSC coordination.

Proposition 1 indicates that when the supplier's selling price is in the range of $\left[\alpha_{\min }^{c w *}, \alpha_{\max }^{c w *}\right]$, the profits for the supplier and the retailers are increased. Therefore, the supplier can obtain a higher profit from the quantity discount contract when the FPSC coordination is achieved.

However, according to Zheng et al. (2017), a decentralized system is unlikely to achieve an optimized result that benefits the whole supply chain. Therefore, the search for a new mechanism that can maximize total profit in an FPSC while also increasing individual profit is warranted. This idea is discussed in the next section.

\section{Coordination of the FPSC under joint procurement}

In this section, the retailers negotiate jointly. The purpose of the retailers' adoption of a joint procurement policy is to lower the supplier's selling price, which will lead to more profit. From the supplier's perspective, joint procurement will potentially increase the ordering quantity, which, in turn, will increase the supplier's profit. Here, $n$ refers to the total number of retailers; $m$ is the number of retailers who form the joint procurement coalition; and $j$ is the number of retailers who do not join the coalition, where $j=n-m$.

\subsection{Scenario I: without a quantity discount contract}

Let superscript $w$ and subscript $C$ denote the case without a quantity 
discount under joint procurement. The ordering cycle $T_{C}^{w}$ is determined by retailer coalition $M$. Therefore, the profit $\pi_{C r}^{w}\left(\alpha_{C i}^{w}, T_{C}^{w}\right)$ of retailer coalition $M$ per unit of time is as follows:

$$
\pi_{C r}^{w}\left(\alpha_{C i}^{w}, T_{C}^{w}\right)=\sum_{i=1}^{m} p_{i} D_{i}-\frac{K_{r}}{T_{C}^{w}}-\sum_{i=1}^{m} h_{i} D_{i} \frac{e^{\theta T_{C}^{w}}-\theta T_{C}^{w}-1}{\theta^{2} T_{C}^{w}}-\sum_{i=1}^{m} \alpha_{C i}^{w} D_{i} \frac{e^{\theta T_{C}^{w}}-1}{\theta T_{C}^{w}} .
$$

Applying the same concept as in Eq. (5), Eq. (16) can be simplified as follows:

$$
\pi_{C r}^{w}\left(\alpha_{C i}^{w}, T_{C}^{w}\right)=\sum_{i=1}^{m}\left(p_{i}-\alpha_{C i}^{w}\right) D_{i}-\frac{K_{r}}{T_{C}^{w}}-\sum_{i=1}^{m} \frac{T_{C}^{w}}{2}\left(h_{i}+\alpha_{C i}^{w} \theta\right) D_{i}
$$

For any given $\alpha_{C i}^{w}$, taking the first derivative of Eq. (17) with respect to $T_{C}^{w}$, we set it equal to 0 ; therefore, $\frac{d \pi_{C r}^{w}\left(\alpha_{C i}^{w}, T_{C}^{w}\right)}{d T_{C}^{w}}=\frac{K_{r}}{\left(T_{C}^{w}\right)^{2}}-\frac{1}{2} \sum_{i=1}^{m}\left(h_{i}+\alpha_{C i}^{w} \theta\right) D_{i}=0$. Taking the second derivative of Eq. (17) with respect to $T_{C}^{w}$, we have $\frac{d^{2} \pi_{C r}^{w}\left(\alpha_{C i}^{w}, T_{C}^{w}\right)}{d\left(T_{C}^{w}\right)^{2}}=-\frac{2 K_{r}}{\left(T_{C}^{w}\right)^{3}}<0$, which means that the retailer's profit function $\pi_{C r}^{w}\left(\alpha_{C i}^{w}, T_{C}^{w}\right)$, is concave to $T_{C}^{w}$. Therefore, we find that the optimal ordering cycle is $T_{C}^{w *}=\sqrt{\frac{2 K_{r}}{\sum_{i=1}^{m}\left(h_{i}+\alpha_{C i}^{w} \theta\right) D_{i}}}$. Substituting $T_{C}^{w^{*}}$ into Eq. (17), we obtain the optimal profit of retailer coalition $M$ in the centralized FPSC as follows:

$$
\pi_{C r}^{w}\left(\alpha_{C i}^{w}, T_{C}^{w *}\right)=\sum_{i=1}^{m}\left(p_{i}-\alpha_{C i}^{w}\right) D_{i}-\sqrt{2 K_{r} \sum_{i=1}^{m}\left(h_{i}+\alpha_{C i}^{w} \theta\right) D_{i}}
$$

Now, a new question is raised. What conditions would entice the retailers to join or remain in the coalition given the total profit, as shown in Eq. (18)? To analyze this matter, we introduce a concave game, also called a cooperation game. A concave game is a totally balanced strategy among players that can be expressed by its concave profit function $v(\cdot)$. Consequently, the game and every subgame have a nonempty core. According to Dror et al. (2012), a concave game implies joint 
procurement. In our case, it means that each retailer in the coalition shall be allocated a proportion of the total profit. Specifically, the amount of profit allocated to each retailer must be larger than that when each retailer operates individually; it is only in this case that there will be an incentive for them to form a coalition.

To verify whether $\left(N, \pi_{C r}^{w}(M)\right)$ is a concave game of the multiple retailers, we set subset $R$ as the number of retailers forming the coalition, where $M \subset R \subseteq N-\{j\}$, and obtain the following lemma:

Lemma 1. $\left(N, \pi_{C r}^{w}(M)\right)$ is a concave game.

Lemma 1 indicates that joint procurement is a concave game. To determine how the profit can be rationally allocated, let $x_{i}$ be the profit of retailer $i$. The retailers will cooperate if $x_{i}$ satisfies the following conditions: (1) efficiency-all profits are fully allocated and $\sum_{i=1}^{m} x_{i}=\pi_{C r}^{w}(M)$; and (2) stability - all the retailers have enough motivation to stay in the coalition only if $x_{i} \geq \pi_{D r i}^{c w}$ (Dror et al., 2012). Note that $x_{i}=\left(p_{i}-\alpha_{C i}^{w}\right) D_{i}-\left(h_{i}+\alpha_{C i}^{w} \theta\right) D_{i} T_{C}^{w}$ if the retailers form a grand coalition $M$, $\sum_{i=1}^{m} x_{i}=\pi_{C r}^{w}(M)$. Then, we can obtain the optimal ordering cycle $T_{C}^{w *}=\sqrt{\frac{2 K_{r}}{\sum_{i=1}^{m}\left(h_{i}+\alpha_{C i}^{w} \theta\right) D_{i}}}$, and the profit of the fresh produce supplier is $\pi_{C s}^{w}\left(\alpha_{C i}^{w}, T_{C}^{w^{*}}\right)=\sum_{i=1}^{m}\left(\alpha_{C i}^{w}-c\right) D_{i}-\frac{K_{s}}{T_{C}^{w^{*}}}$. Comparing the profit of each retailer under joint procurement to the retailers' profit under independent procurement, we obtain $x_{i}-\pi_{D r i}^{c w}=\sqrt{2 K_{r}\left(h_{i}+\alpha_{C i}^{w} \theta\right) D_{i}}-\left(h_{i}+\alpha_{C i}^{w} \theta\right) \sqrt{\frac{2 K_{r}}{\sum_{i=1}^{n}\left(h_{i}+\alpha_{C i}^{w} \theta\right) D_{i}}} \cdot$ We know that 


$$
\frac{\left(h_{i}+\alpha_{C i}^{w} \theta\right) D_{i}}{\sum_{i=1}^{n}\left(h_{i}+\alpha_{C i}^{w} \theta\right) D_{i}}<1 ; \text { therefore, } x_{i}-\pi_{D r i}^{c w}>0 .
$$

Based on the above, the profit of a coalition of retailers can be rationally allocated. Therefore, joint procurement among retailers makes sense.

Proposition 2. A coalition is better than individual operations for both the supplier and the retailers.

Compared to the independent procurement of retailers, joint procurement can improve the profit of both the retailers and the supplier, motivating coalition formation. Based on Proposition 2, we know that retailers can join together to form a coalition and procure fresh produce at a discounted price. However, it is unknown whether the supplier and the retailers will gain more profit if they sign a quantity discount contract. In the following section, we investigate the expected profit of each player under a quantity discount contract and analyze whether a win-win situation can result.

\subsection{Scenario II: with a quantity discount contract}

In actual operations, the quantity discount policy is used extensively to regulate the relationship among retailers and to achieve FPSC coordination. It is natural to inquire about what procurement decisions will be made if the quantity discount contract is implemented. If the profit of each retailer under joint procurement is greater than the retailers' profit under independent procurement, then they will accept the contract. Therefore, the optimization problem of FPSC coordination under a quantity discount contract can be formulated as Eq. (19) and Eq. (20). Here, let superscript $c w$ and subscript $C$ denote the case with a quantity discount under joint procurement.

$$
\max \quad \pi_{C s}^{c w}\left(\alpha_{C}^{c w}, T_{C}^{c w}\right)=\sum_{i=1}^{n}\left(\alpha_{C}^{c w}-c\right) D_{i}-\frac{K_{s}}{T_{C}^{c w}}
$$




$$
\text { s.t. } \quad \pi_{C r}^{c w}\left(\alpha_{C}^{c w}, T_{C}^{c w}\right) \geq \pi_{C r}^{w}\left(\alpha_{C i}^{w}, T_{C}^{w *}\right)
$$

Solving the constraint condition, we have the selling price that the supplier charges the retailer as follows:

$$
\alpha_{C}^{c w}=\left(\sum_{i=1}^{n} \alpha_{C i}^{w} D_{i}+\frac{K_{r}}{T_{C}^{w *}}+\sum_{i=1}^{n} \frac{T_{C}^{w^{*}}}{2}\left(h_{i}+\alpha_{C i}^{w} \theta\right) D_{i}-\frac{K_{r}}{T_{C}^{c w}}-\sum_{i=1}^{n} \frac{h_{i} D_{i} T_{C}^{c w}}{2}\right) /\left(1+\frac{\theta T_{C}^{c w}}{2}\right) \sum_{i=1}^{n} D_{i}
$$

Substituting $\alpha_{C}^{c w}$ into $\pi_{C s}^{c w}\left(\alpha_{C}^{c w}, T_{C}^{c w}\right)$, we obtain the optimal profit of the supplier as follows:

$$
\pi_{C s}^{c w^{*}}\left(T_{C}^{c w}\right)=\frac{\sum_{i=1}^{n} \alpha_{C i}^{w} D_{i}+\frac{K_{r}}{T_{C}^{w *}}+\sum_{i=1}^{n} \frac{T_{C}^{w *}}{2}\left(h_{i}+\alpha_{C i}^{w} \theta\right) D_{i}-\frac{K_{r}}{T_{C}^{c w}}-\sum_{i=1}^{n} \frac{h_{i} D_{i} T_{C}^{c w}}{2}}{1+\frac{\theta T_{C}^{c w}}{2}}-\frac{K_{s}}{T_{C}^{c w}}-\sum_{i=1}^{n} c D_{i}
$$

Taking the first derivative of Eq. (22) with respect to ordering cycle $T_{C}^{c w}$, we obtain the following equation:

$$
\frac{d \pi_{C s}^{c w *}\left(T_{C}^{c w}\right)}{d T_{C}^{c w}}=\frac{-B\left(T_{C}^{c w}\right)^{2}+\left(K_{s}+K_{r}\right) \theta T_{C}^{c w}+K_{s}+K_{r}}{\left(1+\frac{\theta T_{C}^{c w}}{2}\right)^{2}\left(T_{C}^{c w}\right)^{2}}
$$

where $B=\sum_{i=1}^{n} \frac{D_{i} h_{i}}{2}+\frac{\theta}{2}\left(\sum_{i=1}^{n} \alpha_{C i}^{w} D_{i}+\frac{K_{r}}{T_{C}^{c w^{*}}}+\sum_{i=1}^{n} \frac{T_{C}^{c w^{*}}}{2}\left(h_{i}+\alpha_{C i}^{w} \theta\right) D_{i}\right)-\frac{K_{s} \theta^{2}}{4}$

Solving $\frac{d \pi_{C s}^{c w *}\left(T_{C}^{c w}\right)}{d T_{C}^{c w}}=0$, we obtain the following ordering cycle:

$$
T_{C}^{c w *}=\frac{\left(K_{s}+K_{r}\right) \theta+\sqrt{\left(K_{s}+K_{r}\right)^{2} \theta^{2}+4 B\left(K_{s}+K_{r}\right)}}{2 B} .
$$

Taking the second derivative of Eq. (22) with respect to ordering cycle $T_{C}^{c w}$, we obtain the following equation:

$$
\begin{aligned}
\frac{d^{2} \pi_{C s}^{c w^{*}}\left(T_{C}^{c w}\right)}{d\left(T_{C}^{c w}\right)^{2}}= & -2 B\left(T_{C}^{c w}\right)^{3}\left[\left(1+\frac{\theta}{2} T_{C}^{c w}\right)^{2}+\left(1+\frac{3}{2} \theta T_{C}^{c w}+\frac{\theta^{2}}{2}\left(T_{C}^{c w}\right)^{2}\right)\right] \\
& -\left(K_{s}+K_{r}\right)\left[2 T_{C}^{c w}+4 \theta\left(T_{D i}^{c w}\right)^{2}+3 \theta^{2}\left(T_{C}^{c w}\right)^{3}+\frac{3}{4} \theta^{3}\left(T_{C}^{c w}\right)^{4}\right] .
\end{aligned}
$$


It can be seen that $\frac{d^{2} \pi_{C s}^{c w *}\left(T_{C}^{c w}\right)}{d\left(T_{C}^{c w}\right)^{2}}<0$ from Eq. (24) has a maximum value occurring at $T_{C}^{c w}=T_{C}^{c w *}$.

Proposition 3. For the joint procurement case with one supplier and multiple retailers, when the supplier's selling price $\alpha_{C}^{c w}$ satisfies $\alpha_{C}^{c w}=\left\{\begin{array}{l}\alpha_{C}^{c w *}, T_{C}^{c w} \geq T_{C}^{c w^{*}} \\ \alpha_{C i}^{w}, T_{C}^{c w}<T_{C}^{c w *}\end{array}\right.$, where $\quad \alpha_{\min }^{c w *} \leq \alpha_{C}^{c w^{*}} \leq \alpha_{\max }^{c w *} \quad, \quad \alpha_{\min }^{c w *}=\left(\sum_{i=1}^{n} \alpha_{C i}^{w} D_{i}-\frac{K_{s}}{T_{C}^{w *}}+\frac{K_{s}}{T_{C}^{c w^{*}}}\right) / \sum_{i=1}^{n} D_{i}$ and $\alpha_{\max }^{c w^{*}}=\left(\sum_{i=1}^{n} \alpha_{C i}^{w} D_{i}+\frac{K_{r}}{T_{C}^{w^{*}}}+\sum_{i=1}^{n} \frac{T_{C}^{w^{*}}}{2}\left(h_{i}+\alpha_{C i}^{w} \theta\right) D_{i}-\frac{K_{r}}{T_{C}^{c w^{*}}}-\sum_{i=1}^{n} \frac{h_{i} D_{i} T_{C}^{c w^{*}}}{2}\right) / \sum_{i=1}^{n} D_{i}\left(1+\frac{\theta T_{C}^{c w^{*}}}{2}\right)$, the quantity discount contract $\left(\alpha_{C}^{c w^{*}}, T_{C}^{c w^{*}}\right)$ can be accepted by the supplier and the retailers to coordinate the FPSC, and the optimal profit allocation of the retailers, $x_{i}\left(\alpha_{C}^{c w *}, T_{C}^{c w *}\right)$, can be realized.

From Proposition 3, we find that the solution to this programming problem can improve the profit of both the supplier and the retailers. Furthermore, if supply chain optimization is achieved, then the quantity discount contract guarantees a win-win result for the supplier and the retailers. Additionally, when the profit of the coalition is rationally allocated to each retailer such that the profit of each party under the current policy is greater than that under independent procurement, the members will stay. This occurs when the price that the supplier charges the retailer is in the range of $\left[\alpha_{\min }^{c w^{*}}, \alpha_{\max }^{c w *}\right]$.

Corollary 1. For joint procurement, when $\alpha_{C}^{c w *}$ is in the range of $\left[\alpha_{\min }^{c w *}, \alpha_{\max }^{c w *}\right]$, the profits of both the supplier and each retailer decrease with an increase in the deterioration rate. The ordering cycle is also shortened with an increase in the deterioration rate.

Corollary 1 shows that if $\alpha_{C}^{c w^{*}} \in\left[\alpha_{\min }^{c w^{*}}, \alpha_{\max }^{c w^{*}}\right]$, then the profits of both the supplier and each retailer decrease with an increase in the deterioration rate. Additionally, 
$T_{C}^{c w}$ decreases when $\theta$ increases; this is in line with the actual management status. In fact, retailers need to shorten the ordering cycle when fresh produce products are at the end of their shelf life. That is, it is necessary to adjust the ordering cycle when the deterioration rate of fresh produce decreases sharply. Simultaneously, if the supplier and the retailer expect to gain more profit, then they can invest in efforts to maintain the freshness of products and to slow the deterioration rate.

\section{Coordination of the FPSC under joint procurement with coordination cost}

According to Balcik et al. (2010), coordination initiatives bear some costs, such as time and money costs. Consequently, the coordination cost may significantly affect the profits associated with joint procurement. Therefore, it is meaningful to discuss how to maximize the profit of the FPSC, that is, to discuss FPSC coordination issues when considering the coordination cost. For $\forall M \subseteq N$, let $c(N)$ denote the coordination cost; it satisfies the condition as follows: $(1) c(\varnothing)=0$; (2) for any given $M \subseteq N, c(M) \leq c(N)$, and $c(N)$ increases as the size of the coalition grows. In particular, we assume that the coordination cost faced by the supply chain players is a linear function of coalition size. The coordination cost for the coalition is given as $c(M)=k m+b$, where $m$ represents the number of retailers who join the coalition, $k$ represents the coefficient of coalition size to the coordination cost and $b$ represents a constant. Let superscript $e w$ and subscript $C$ denote the case with the quantity discount contract under joint procurement when considering the coordination cost. Therefore, the profit of the coalition of retailers per unit of time is given as follows:

$$
\pi_{C r}^{e w}\left(\alpha_{C}^{e w}, T_{C}^{e w}\right)=\sum_{i=1}^{n} p_{i} D_{i}-\frac{K_{r}+k n+b}{T_{C}^{e w}}-\sum_{i=1}^{n} h_{i} D_{i} \frac{e^{\theta T_{C}^{e w}}-\theta T_{C}^{e w}-1}{\theta^{2} T_{C}^{e w}}-\sum_{i=1}^{n} \alpha_{C}^{e w} D_{i} \frac{e^{\theta T_{C}^{e w}}-1}{\theta T_{C}^{e w}} .
$$

Applying the same concept as in Eq. (5), Eq. (25) can be simplified as follows: 


$$
\pi_{C r}^{e w}\left(\alpha_{C}^{e w}, T_{C}^{e w}\right)=\sum_{i=1}^{n}\left(p_{i}-\alpha_{C}^{e w}\right) D_{i}-\frac{K_{r}+k n+b}{T_{C}^{e w}}-\sum_{i=1}^{n} \frac{T_{C}^{e w}}{2}\left(h_{i}+\alpha_{C}^{e w} \theta\right) D_{i} .
$$

For any given $\alpha_{0}$, taking the first derivative of Eq. (26) with respect to ordering cycle $T_{C}^{e w}$, we set it equal to 0 ; therefore, $\frac{d \pi_{C r}^{e w}\left(\alpha_{C}^{e w}, T_{C}^{e w}\right)}{d T_{C}^{e w}}=\frac{K_{r}+k n+b}{\left(T_{C}^{e w}\right)^{2}}-\frac{1}{2} \sum_{i=1}^{n}\left(h_{i}+\alpha_{C}^{e w} \theta\right) D_{i}=0$. Taking the second derivative of Eq. (26) with respect to $T_{C}^{e w}$, we get $\frac{d^{2} \pi_{C r}^{e w}\left(\alpha_{C}^{e w}, T_{C}^{e w}\right)}{d T_{C}^{e w 2}}=-\frac{2 K_{r}+k n+b}{\left(T_{C}^{e w}\right)^{3}}<0$; hence, $\pi_{C r}^{e w}\left(\alpha_{C}^{e w}, T_{C}^{e w}\right)$ is concave to $T_{C}^{e w}$. Therefore, we find that the optimal ordering cycle is as follows:

$$
T_{C}^{e w *}=\sqrt{\frac{2\left(K_{r}+k n+b\right)}{\sum_{i=1}^{n}\left(h_{i}+\alpha_{C}^{e w} \theta\right) D_{i}}}
$$

Substituting $T_{C}^{e w *}$ into Eq. (26), we obtain the optimal profit of the coalition of retailers in the centralized FPSC as follows:

$$
\pi_{C r}^{e w}\left(\alpha_{C}^{e w}, T_{S}^{e w *}\right)=\sum_{i=1}^{n}\left(p_{i}-\alpha_{C}^{e w}\right) D_{i}-\sqrt{2\left(K_{r}+k n+b\right) \sum_{i=1}^{n}\left(h_{i}+\alpha_{C}^{e w} \theta\right) D_{i}}
$$

Then, the profit of the supplier is as follows:

$$
\pi_{C s}^{e w}\left(\alpha_{C}^{e w}, T_{N}^{e w *}\right)=\sum_{i=1}^{n}\left(\alpha_{C}^{e w}-c\right) D_{i}-K_{s} \sqrt{\frac{\sum_{i=1}^{n}\left(h_{i}+\alpha_{C}^{e w} \theta\right) D_{i}}{2\left(K_{r}+k n+b\right)}} .
$$

When the supplier and the retailers sign the quantity discount contract, the optimization problem of FPSC coordination can be formulated as follows:

$$
\begin{gathered}
\max \pi_{C s}^{e w}\left(\alpha_{C}^{e w}, T_{C}^{e w}\right)=\sum_{i=1}^{n}\left(\alpha_{C}^{e w}-c\right) D_{i}-\frac{K_{s}}{T_{C}^{e w}} \\
\text { s.t. } \pi_{C r}^{e w}\left(\alpha_{C}^{e w}, T_{C}^{e w}\right) \geq \pi_{C r}^{w}\left(\alpha_{C}^{w}, T_{C}^{w}\right) .
\end{gathered}
$$


Solving the constraint condition, we have the selling price that the supplier charges the retailer as follows:

$$
\alpha_{C}^{e w}=\left(\sum_{i=1}^{n} \alpha_{C}^{w} D_{i}+\frac{K_{r}+k n+b}{T_{C}^{e w *}}+\sum_{i=1}^{n} \frac{T_{C}^{e w *}}{2}\left(h_{i}+\alpha_{C}^{w} \theta\right) D_{i}-\frac{K_{r}+k n+b}{T_{C}^{e w}}-\sum_{i=1}^{n} \frac{h_{i} D_{i} T_{C}^{e w}}{2}\right) /\left(1+\frac{\theta T_{C}^{e w}}{2}\right) \sum_{i=1}^{n} D_{i} .
$$

Substituting $\alpha_{C}^{e w}$ into Eq. (30), we obtain the optimal profit of the supplier as follows:

$$
\pi_{C s}^{e w *}\left(T_{C}^{e w}\right)=\frac{\sum_{i=1}^{n} \alpha_{C}^{w} D_{i}+\frac{K_{r}+k n+b}{T_{C}^{e w *}}+\sum_{i=1}^{n} \frac{T_{C}^{e w *}}{2}\left(h_{i}+\alpha_{C}^{w} \theta\right) D_{i}-\frac{K_{r}+k n+b}{T_{C}^{e w}}-\sum_{i=1}^{n} \frac{h_{i} D_{i} T_{C}^{e w}}{2}}{1+\frac{\theta T_{C}^{e w}}{2}}-\frac{K_{s}}{T_{C}^{e w}}-\sum_{i=1}^{n} c D_{i} .
$$

Taking the first derivative of Eq. (33) with respect to ordering cycle $T_{C}^{e w}$, we obtain the following:

$$
\frac{d \pi_{C s}^{e w *}\left(T_{C}^{e w}\right)}{d T_{C}^{e w}}=\frac{-C\left(T_{C}^{e w}\right)^{2}+\left(K_{r}+k n+b+K_{s}\right) \theta T_{C}^{e w}+K_{s}+K_{r}+k n+b}{\left(1+\frac{\theta T_{C}^{e w}}{2}\right)^{2}\left(T_{C}^{e w}\right)^{2}},
$$

where $C=\sum_{i=1}^{n} \frac{D_{i} h_{i}}{2}+\frac{\theta}{2}\left(\sum_{i=1}^{n} \alpha_{C}^{w} D_{i}+\frac{K_{r}+k n+b}{T_{C}^{e w *}}+\sum_{i=1}^{n} \frac{T_{C}^{e w *}}{2}\left(h_{i}+\alpha_{C}^{w} \theta\right) D_{i}\right)-\frac{K_{s} \theta^{2}}{4}$.

Taking the second derivative of Eq. (33) with respect to ordering cycle $T_{C}^{e w}$, we obtain the following:

$$
\begin{aligned}
\frac{d^{2} \pi_{C s}^{e w *}\left(T_{C}^{e w}\right)}{d\left(T_{C}^{e w}\right)^{2}}= & -2 C\left(T_{C}^{e w}\right)^{3}\left[\left(1+\frac{\theta}{2} T_{C}^{e w}\right)^{2}+\left(1+\frac{3}{2} \theta T_{C}^{e w}+\frac{\theta^{2}}{2}\left(T_{C}^{e w}\right)^{2}\right)\right] \\
& -\left(K_{s}+k n+b+K_{r}\right)\left[2 T_{C}^{e w}+4 \theta\left(T_{C}^{e w}\right)^{2}+3 \theta^{2}\left(T_{C}^{e w}\right)^{3}+\frac{3}{4} \theta^{3}\left(T_{C}^{e w}\right)^{4}\right] .
\end{aligned}
$$

Eq. (35) shows that $\frac{d^{2} \pi_{C s}^{e w *}\left(T_{C}^{e w}\right)}{d\left(T_{C}^{e w}\right)^{2}}<0$; it has a maximum value occurring at $T_{C}^{e w}=T_{C}^{e w *}$

Solving $\frac{d \pi_{C s}^{e w *}\left(T_{C}^{e w}\right)}{d T_{C}^{e w}}=0$, we obtain the optimal ordering cycle: 


$$
T_{C}^{e w *}=\frac{\left(K_{s}+K_{r}+k n+b\right) \theta+\sqrt{\left(K_{s}+K_{r}+k n+b\right)^{2} \theta^{2}+4 C\left(K_{s}+K_{r}+k n+b\right)}}{2 C} .
$$

The optimal ordering cycle shows the target point for the operational plan of an FPSC after the coordination cost is considered.

Proposition 4. For the joint procurement case with the coordination cost, when the selling price that the supplier charges the retailer $\alpha_{C}^{e}{ }^{w}$ satisfies $\alpha_{C}^{e w}=\left\{\begin{array}{l}\alpha_{C}^{e w *}, T_{C}^{e w} \geq T_{C}^{e w *} \\ \alpha_{C}^{w}, T_{C}^{e w}<T_{C}^{e w *}\end{array}\right.$, where $\alpha_{\min }^{e w *} \leq \alpha_{C}^{e w *} \leq \alpha_{\max }^{e w *}, \quad \alpha_{\min }^{e w *}=\left(\sum_{i=1}^{n} \alpha_{C}^{w} D_{i}-\frac{K_{s}}{T_{D}^{e w *}}+\frac{K_{s}}{T_{C}^{e w *}}\right) / \sum_{i=1}^{n} D_{i}$ and

$$
\alpha_{\max }^{e w *}=\left(\sum_{i=1}^{n} \alpha_{C}^{w} D_{i}+\frac{K_{r}+k n+b}{T_{D}^{e w *}}+\sum_{i=1}^{n} \frac{T_{D}^{e w *}}{2}\left(h_{i}+\alpha_{C}^{w} \theta\right) D_{i}-\frac{K_{r}+k n+b}{T_{C}^{e w *}}-\sum_{i=1}^{n} \frac{h_{i} D_{i} T_{C}^{e w *}}{2}\right) / \sum_{i=1}^{n} D_{i}\left(1+\frac{\theta T_{C}^{e w *}}{2}\right),
$$

the coordination of an FPSC can be achieved by the quantity discount contract $\left(\alpha_{C}^{e w *}, T_{C}^{e w *}\right)$ and the optimal profit allocation of the retailer $x_{i}\left(\alpha_{C}^{e w *}, T_{C}^{e w *}\right)$.

Proposition 4 has several managerial implications that strengthen the importance of joint procurement properties in determining the supplier's optimal selling price and the ordering cycle. When the retailers join together and form the coalition, Proposition 4 provides the supplier with a simple rule, via the concept of cooperation, to determine the supplier's selling price under different ordering cycles. Even when the ordering cycle is longer than the optimal ordering cycle, the value range of the supplier's optimal selling price is a critical principle. In this situation, the principle suggests that the supplier can control the price in the range of $\left[\alpha_{\min }^{e w *}, \alpha_{\max }^{e w *}\right]$ to maximize the supplier's own profit and to ensure the profit of the retailer coalition as well. Together, these results provide significant insights into the joint procurement problem of FPSCs under a quantity discount contract.

Interestingly, the greater the number of retailers in the coalition is, the higher the coordination cost and the lower the profit for each retailer. Determining the optimal size of the coalition is important for the FPSC, as this choice affects the profit not only 
for individual retailers but also for the whole coalition.

Proposition 5. When the number of retailers in the coalition satisfies $m \in\left[0, \frac{K_{r} \sum_{i=1}^{n}\left(h_{i}+\alpha_{C}^{w} \theta\right) D_{i}}{k\left(h_{i}+\alpha_{C}^{w} \theta\right) D_{i}}-\frac{K_{r}+b}{k}\right]$, the profit of each retailer is not less than that in the case without a contract under joint procurement. In other words, when $m$ is beyond this range, the profit will decrease.

Proposition 5 indicates that when the size of coalition $M$ reaches a certain range, joint procurement among retailers makes sense, as the profit will be higher. However, if the number of retailers in the coalition is too large, then the profit of each retailer will decrease due to the higher coordination cost. In other words, in a coalition that is too large, negotiating is troublesome and increases the cost. This means that one retailer can work with others, but if all retailers form a coalition, then the coordination cost will be too high.

We now discuss how the quantity discount contract can be implemented in practice. The supplier and the coalition of retailers first agree on a quantity discount $\operatorname{contract}\left(\alpha_{C}^{e w}, T_{C}^{e w}\right)$. The supplier can observe the retail price and the demand rate determined by the retailers. Regarding $Q$, the supplier can conduct a check of the ordering quantity when the contract is reached. The ordering cycle of the retailers can be determined by $T_{C}^{e w *}=\sqrt{\frac{2\left(K_{r}+k n+b\right)}{\sum_{i=1}^{n}\left(h_{i}+\alpha_{C}^{w} \theta\right) D_{i}}}$. According to the contract, the selling price that the supplier charges the retailers is in the range of $\left[\alpha_{\min }^{e w *}, \alpha_{\max }^{e w *}\right]$, where

$$
\alpha_{\min }^{e w *}=\left(\sum_{i=1}^{n} \alpha_{C}^{w} D_{i}-\frac{K_{s}}{T_{D}^{e w *}}+\frac{K_{s}}{T_{C}^{e w^{*}}}\right) / \sum_{i=1}^{n} D_{i}
$$
and

$$
\alpha_{\text {max }}^{e w *}=\left(\sum_{i=1}^{n} \alpha_{C}^{w} D_{i}+\frac{K_{r}+k n+b}{T_{D}^{e n *}}+\sum_{i=1}^{n} \frac{T_{D}^{e w *}}{2}\left(h_{i}+\alpha_{C}^{w} \theta\right) D_{i}-\frac{K_{r}+k n+b}{T_{C}^{e w *}}-\sum_{i=1}^{n} \frac{h_{i} D_{i} T_{C}^{e w *}}{2}\right) / \sum_{i=1}^{n} D_{i}\left(1+\frac{\theta T_{C}^{e w *}}{2}\right) .
$$


From the above discussion, we derive some instructions from the model. In practice, it is necessary to encourage retailers to form a grand coalition through negotiation and to adopt a joint procurement strategy. In addition, if the coordination cost is too high, then they can outsource joint procurement to a third-party logistics service supplier to minimize the operational cost.

\section{Numerical examples}

In this section, we present some numerical examples to illustrate the theoretical outcomes obtained in the previous sections. The supply of durians from Malaysia, one of the countries along the BRI, is presented as an example. Several supermarkets in China purchase durians from the fruit supplier in Malaysia. We are particularly interested in the effects of different policies and related parameters on the performance of each party. The numerical comparisons will illustrate the gaps between independent procurement and joint procurement in terms of each party's expected profit, depending on the system parameters.

\subsection{Numerical analysis}

Here, we assume that the FPSC consists of one supplier and four retailers. For better illustration, instead of using dummy numbers, the FPSC in question is modified from a dataset containing four supermarket data sets. We set the deterioration rate as $\theta=0.02$, the supplier's fixed ordering cost as $K_{s}=¥ 100$ (CNY) per order, the retailer's fixed ordering cost as $K_{r}=¥ 60$ per order and the supplier's procurement (or production) cost as $c=¥ 1.5$ per unit. The different parameters of retailer $i$ are summarized in Table 2.

Table 2 Parameters of retailer $i$

\begin{tabular}{ccccc}
\hline Retailer $i$ & 1 & 2 & 3 & 4 \\
\hline$D_{i}$ & 100 & 150 & 120 & 125 \\
$h_{i}(\mathrm{CNY})$ & 0.8 & 0.5 & 0.7 & 0.9
\end{tabular}




\begin{tabular}{lllll}
$p_{i}(\mathrm{CNY})$ & 5.0 & 4.8 & 4.5 & 5.2 \\
\hline
\end{tabular}

Using the parameters in Table 2, we apply them to the previously analyzed scenarios. Next, we analyze how the supplier's selling price and the retailers' ordering cycle impact the profits of both the supplier and the retailers.

Table 3 Profit of the supplier and the retailers under independent procurement

\begin{tabular}{cccccc}
\hline$\alpha_{D i}^{c w}$ & \multicolumn{5}{c}{ Profit (CNY) } \\
\cline { 2 - 6 }$(\mathrm{CNY})$ & Supplier & Retailer 1 & Retailer 2 & Retailer 3 & Retailer 4 \\
\hline 2.8 & 288.91 & 118.65 & 199.96 & 99.66 & 180.25 \\
2.7594 & 548.89 & 121.97 & 205.50 & 103.35 & 180.25 \\
2.6656 & 502.46 & 131.47 & 219.76 & 114.76 & 192.13 \\
2.5743 & 457.26 & 140.73 & 233.64 & 125.86 & 203.70 \\
2.4968 & 418.90 & 148.58 & 245.42 & 135.29 & 213.51 \\
2.3619 & 352.12 & 162.25 & 265.93 & 151.70 & 230.60 \\
2.2342 & 288.91 & 175.19 & 285.34 & 167.22 & 246.78 \\
\hline
\end{tabular}

The results in Table 3, showing the profit of the supplier and retailers $i$ under independent procurement, verify Proposition 1. Table 3 also indicates that the value of the supplier's profit is at a maximum when the selling price that the supplier charges the retailers is $\alpha_{\max }^{c w}=2.7594$, whereas the maximum value of the retailers' profit occurs when the selling price that the supplier charges is $\alpha_{\min }^{c w}=2.2342$. When $\alpha_{D i}^{c w}=2.8$, it represents the situation that the supplier and the retailers don't achieve the supply chain coordination. In this case, the retailers are unwilling to corporate with the supplier, the supplier's profit is lower because of the higher selling price and less ordering quantity. While the supplier and the retailers can earn more profit than in the case without a contract, where $\alpha_{D i}^{c w}=2.8$, when the supplier's optimal selling price satisfies $\alpha_{\min }^{c w^{*}} \leq \alpha_{D i}^{c w^{*}} \leq \alpha_{\max }^{c w^{*}}$. In summary, an FPSC with a quantity discount contract is more optimized than an FPSC without a contract.

The results in Table 4 verify Proposition 3. 
Table 4 Profit of the supplier and the retailers under joint procurement

\begin{tabular}{cccccc}
\hline$\alpha_{C}^{c w}$ & \multicolumn{5}{c}{ Profit $(\mathrm{CNY})$} \\
\cline { 2 - 6 }$(\mathrm{CNY})$ & Supplier & Retailer 1 & Retailer 2 & Retailer 3 & Retailer 4 \\
\hline 2.8 & 465.73 & 177.19 & 261.12 & 159.38 & 239.45 \\
2.7468 & 508.71 & 177.19 & 261.12 & 159.38 & 239.45 \\
2.7306 & 500.67 & 178.82 & 263.57 & 161.34 & 241.49 \\
2.7143 & 492.61 & 180.46 & 266.03 & 163.31 & 243.54 \\
2.7034 & 487.21 & 181.56 & 267.68 & 164.63 & 244.90 \\
2.6817 & 476.47 & 183.74 & 270.96 & 167.24 & 247.63 \\
2.6600 & 465.73 & 185.92 & 274.23 & 169.86 & 250.35 \\
\hline
\end{tabular}

The results show the profit of the supplier and retailers $i$ under joint procurement. Table 4 indicates that the retailers can earn more profit using joint procurement than they can with independent procurement. Moreover, the profit of the supplier under joint procurement is increased compared to the supplier's profit under independent procurement. The threshold of the supplier's selling price is smaller after the retailers engage in joint procurement (Table 4 vs. Table 3 ).

Table 5 shows that the supplier's selling price decreases with an increase in the deterioration rate, the ordering cycle of the retailer gradually becomes shorter, and the ordering frequency increases.

Table 5 The supplier's selling price and the retailers' ordering cycle with different deterioration rates

\begin{tabular}{ccccc}
\hline \multirow{2}{*}{$\theta$} & \multicolumn{2}{c}{ Independent procurement } & \multicolumn{2}{c}{ Joint procurement } \\
\cline { 2 - 5 } & $\alpha_{D i}^{c w^{*}}(\mathrm{CNY})$ & $T_{D i}^{c w^{*}}$ & $\alpha_{C}^{c w^{*}}(\mathrm{CNY})$ & $T_{C}^{c w^{*}}$ \\
\hline 0.01 & 2.5019 & 1.3658 & 2.7055 & 0.9376 \\
0.02 & 2.4968 & 1.3420 & 2.7034 & 0.9219 \\
0.03 & 2.4917 & 1.3195 & 2.7014 & 0.9070 \\
0.04 & 2.4867 & 1.2981 & 2.6408 & 0.6230 \\
\hline
\end{tabular}


Comparing independent procurement with joint procurement shows that under joint procurement, the supplier's selling price is higher and the retailer's ordering cycle is shorter.

Tables 6 and 7 demonstrate that the profits of both the supplier and the retailers decline as the deterioration rate increases, regardless of whether they are using independent procurement or joint procurement.

Table 6 Profit of the supplier and the retailers with different deterioration rates under

\begin{tabular}{cccccc}
\multicolumn{5}{c}{ independent procurement } \\
\hline$\theta$ & Supplier & Retailer 1 & Retailer 2 & Retailer 3 & Retailer 4 \\
\cline { 2 - 6 } & 422.72 & 149.54 & 247.00 & 136.43 & 214.37 \\
0.01 & 418.90 & 148.58 & 245.42 & 135.29 & 213.51 \\
0.02 & 415.10 & 147.65 & 243.89 & 134.19 & 212.68 \\
0.03 & 411.38 & 146.73 & 242.41 & 133.11 & 211.85 \\
\hline
\end{tabular}

Table 7 Profit of the supplier and the retailers with different deterioration rates under joint procurement

\begin{tabular}{cccccc}
\hline & \multicolumn{5}{c}{ Profit (CNY) } \\
\cline { 2 - 6 }$\theta$ & Supplier & Retailer 1 & Retailer 2 & Retailer 3 & Retailer 4 \\
\hline 0.01 & 490.06 & 182.02 & 268.84 & 165.31 & 245.36 \\
0.02 & 487.21 & 181.56 & 267.68 & 164.63 & 244.90 \\
0.03 & 484.44 & 181.09 & 266.54 & 163.95 & 244.44 \\
0.04 & 404.17 & 167.16 & 237.40 & 145.03 & 229.31 \\
\hline
\end{tabular}

However, comparing Table 6 and Table 7 clearly shows that the supplier and the retailers can obtain more profit under joint procurement than under independent procurement.

The numerical analysis indicates that coordinating FPSCs through quantity discount contracts makes sense regardless of how much the parameters change. 
When the supplier's selling price and the retailers' ordering cycle satisfy the contract, the profit of the supplier and the profit of the retailer are significantly higher than that without the contract. Table 5 shows that regardless of how much the parameters change, the closer $\left(\alpha_{C}^{c w}, T_{C}^{c w}\right)$ is to $\left(\alpha_{C}^{c w *}, T_{C}^{c w *}\right)$, the easier it is to coordinate the FPSC. In addition, the entire supply chain, the supplier and the retailers are all more profitable when the parameters are in the range of $\left(\alpha_{C}^{c w *}, T_{C}^{c w *}\right)$.

When the coordination cost is considered, the fixed ordering cost of coalition $N$ is calculated, as shown in Table 8.

Table 8 Parameters of the fixed ordering costs in coalition $N$

\begin{tabular}{cccccc}
\hline$N$ & $\{1\}$ & $\{2\}$ & $\{3\}$ & $\{4\}$ & $\{1,2\}$ \\
$K_{r}+c(N)$ & 60 & 60 & 60 & 60 & 75.84 \\
$N$ & $\{1,3\}$ & $\{1,4\}$ & $\{2,3\}$ & $\{2,4\}$ & $\{3,4\}$ \\
$K_{r}+c(N)$ & 77.62 & 90.63 & 68.26 & 76.47 & 86.44 \\
$N$ & $\{1,2,3\}$ & $\{1,2,4\}$ & $\{1,3,4\}$ & $\{2,3,4\}$ & $\{1,2,3,4\}$ \\
$K_{r}+c(N)$ & 93.54 & 94.80 & 109.54 & 99.86 & 112.62 \\
\hline
\end{tabular}

Similarly, the characteristic function values of $\left(N, \pi_{C r}^{c w^{*}}\right)$ are listed in Table 9 .

Table 9 Parameters of the characteristic function values of $\pi_{C r}^{c w^{*}}(N)$

\begin{tabular}{cccccc}
\hline$N$ & $\{1\}$ & $\{2\}$ & $\{3\}$ & $\{4\}$ & $\{1,2\}$ \\
$\pi_{C r}^{c w^{*}}(N)$ & 0.819 & 0.795 & 0.840 & 0.971 & 1.015 \\
$N$ & $\{1,3\}$ & $\{1,4\}$ & $\{2,3\}$ & $\{2,4\}$ & $\{3,4\}$ \\
$\pi_{C r}^{c w^{*}}(N)$ & 1.031 & 1.034 & 1.084 & 1.112 & 1.070 \\
$N$ & $\{1,2,3\}$ & $\{1,2,4\}$ & $\{1,3,4\}$ & $\{2,3,4\}$ & $\{1,2,3,4\}$ \\
$\pi_{C r}^{c w *}(N)$ & 1.135 & 1.192 & 1.127 & 1.171 & 1.254 \\
\hline
\end{tabular}


Taking the parameters in Tables 8 and 9, we apply them to the previously analyzed scenarios. Now, we can obtain the profits of the supplier and the retailers under joint procurement considering the coordination cost.

The effect of the coordination cost on the FPSC under joint procurement is shown in Table 10.

Table 10 Profit of the supplier and the retailers under joint procurement with the coordination cost

\begin{tabular}{crrrrr}
\hline \multirow{2}{*}{$\alpha_{C}^{e w}$} & \multicolumn{5}{c}{ Profit (CNY) } \\
\cline { 2 - 6 }$(\mathrm{CNY})$ & Supplier & Retailer 1 & Retailer 2 & Retailer 3 & Retailer 4 \\
\hline 2.8 & 489.09 & 155.76 & 239.53 & 136.49 & 209.74 \\
2.8378 & 565.83 & 155.76 & 239.53 & 136.49 & 209.74 \\
2.7794 & 531.96 & 164.55 & 243.01 & 144.44 & 223.41 \\
2.7489 & 506.96 & 169.61 & 250.60 & 150.51 & 229.73 \\
2.7213 & 489.09 & 178.40 & 263.29 & 162.66 & 249.97 \\
\hline
\end{tabular}

Clearly, the profit is higher under independent procurement and lower when coordination is not considered. These results occurred because the ordering cycle increases and the ordering frequency decreases when the coordination cost is considered. Furthermore, according to Proposition 4, the optimal selling price that the supplier charges changes because it is also related to the coordination cost and the retailers' ordering cycle. This relationship exemplifies the managerial complexity of an FPSC that consists of one supplier and multiple retailers. Table 10 illustrates that the total profit of an FPSC under a quantity discount contract is higher than that without a contract. This result implies the efficiency and significance of quantity discount contracts in coordinating an FPSC under joint procurement. 


\subsection{Sensitivity analysis}

In this subsection, a sensitivity analysis of demand and the deterioration rate is performed based on the above example; the results are shown in Table 11 and Table 12. We carried out the sensitivity analysis in terms of different levels of demand and different deterioration rates. Table 11 shows the sensitivity of the parameters to the selling price for the retailer, the ordering cycle and the expected total cost per unit under independent procurement and joint procurement. Here, $\alpha$ is the supplier's selling price to retailer, $T$ is the retailer's ordering cycle, and $\theta$ is the fresh product's deterioration rate.

Table 11 Sensitivity analysis of demand and the deterioration rate under independent procurement

\begin{tabular}{ccccc}
\hline \multirow{2}{*}{ Parameters } & Changes (in \%) & $\alpha_{i}$ & $T_{i}$ & $\pi_{i}$ \\
\hline \multirow{2}{*}{$D$} & -20 & +0.0027 & +0.1180 & -0.1704 \\
& -10 & +0.0024 & +0.0541 & -0.0855 \\
& +10 & -0.0029 & -0.0465 & +0.0859 \\
& +20 & -0.0059 & -0.0871 & +0.1720 \\
& -20 & +0.1102 & +0.1975 & +0.2682 \\
& -10 & +0.0512 & +0.0864 & +0.1374 \\
& +10 & -0.0394 & -0.0741 & -0.1407 \\
& +20 & -0.0787 & -0.1235 & -0.2842 \\
\hline
\end{tabular}

Table 12 shows the sensitivity of the parameters to the selling price for the retailer, the ordering cycle and the expected total cost per unit under joint procurement.

Table 12 Sensitivity analysis of demand and the deterioration rate under joint procurement

\begin{tabular}{ccccc} 
Parameters & Changes (in \%) & $\alpha_{i}$ & $T_{i}$ & $\pi_{i}$ \\
\hline \multirow{2}{*}{$D$} & -20 & +0.0016 & +0.1014 & -0.2000 \\
& -10 & +0.0010 & +0.0471 & -0.1000 \\
\hline
\end{tabular}




\begin{tabular}{ccccc}
\hline & & & & \\
& +10 & -0.0027 & -0.0333 & +0.1806 \\
+20 & -0.0035 & -0.0675 & +0.2336 \\
& -20 & +0.0258 & +0.2209 & +0.4689 \\
& -10 & +0.0148 & +0.0930 & +0.2345 \\
& +10 & -0.0148 & -0.0814 & -0.2345 \\
& +20 & -0.0332 & -0.1395 & -0.4689 \\
\hline
\end{tabular}

Compared with the deterioration rate, demand plays a minor significant role, but as we expected, the selling price for the retailer and the ordering cycle are decreased when the level of demand is increased. That is, the total profit is increased by increasing demand.

The supplier's selling price for the retailer and the ordering cycle are highly dependent on the deterioration rate. That is, the total profit is decreased if the deterioration rate is raised.

\section{Extension}

It is known that demand for a product is not always certain. When it is stochastic, will the structure of the optimal policy obtained in the deterministic case change for the stochastic case? Therefore, it is interesting to analyze the joint procurement policy when the demand is stochastic. Consequently, we have accounted for stochastic demand in developing the model. In this section, we set consumers' demands to follow a normal distribution considering that these uncertainties make the problem more similar to real-life supply and demand issues. Here, we assume the demand follows the normal distribution, $D \sim\left(\mu, \sigma^{2}\right)$. Therefore, the density function of the normal distribution is given by $f(x)=\frac{1}{\sqrt{2 \pi \sigma^{2}}} e^{-(x-\mu)^{2} / 2 \sigma^{2}}$. Let superscript $e$ and subscript $C$ denote the case with a quantity discount under joint procurement. Therefore, the objective function and constraint of this model are given as follows: 


$$
\begin{gathered}
\max \pi_{C s}^{e}\left(\alpha_{C}^{e}, T_{C}^{e}\right)=\sum_{i=1}^{n}\left(\alpha_{C}^{e}-c\right) \int_{0}^{+\infty} x f(x)-\frac{K_{s}}{T_{C}^{e}} \\
\text { s.t. } \pi_{C r}^{e}\left(\alpha_{C}^{e}, T_{C}^{e}\right) \geq \pi_{C r}^{w}\left(\alpha_{C i}^{w}, T_{C}^{w *}\right)
\end{gathered}
$$

Solving the constraint condition, we have the selling price that the supplier charges the retailer as follows:

$$
\begin{aligned}
& \alpha_{C}^{e}=\left(\sum_{i=1}^{n} \alpha_{C i}^{w} \int_{0}^{+\infty} x \frac{1}{\sqrt{2 \pi \sigma^{2}}} e^{-(x-\mu)^{2} / 2 \sigma^{2}} d x+\frac{K_{r}}{T_{C}^{w^{*}}}+\sum_{i=1}^{n} \frac{T_{C}^{w^{*}}}{2}\left(h_{i}+\alpha_{C i}^{w} \theta\right) \int_{0}^{+\infty} x \frac{1}{\sqrt{2 \pi \sigma^{2}}} e^{-(x-\mu)^{2} / 2 \sigma^{2}} d x\right. \\
& \left.-\frac{K_{r}}{T_{C}^{e}}-\sum_{i=1}^{n} \frac{h_{i} \int_{0}^{+\infty} x \frac{1}{\sqrt{2 \pi \sigma^{2}}} e^{-(x-\mu)^{2} / 2 \sigma^{2}} d x T_{C}^{e}}{2}\right) /\left(1+\frac{\theta T_{C}^{e}}{2}\right) \sum_{i=1}^{n} \int_{0}^{+\infty} x \frac{1}{\sqrt{2 \pi \sigma^{2}}} e^{-(x-\mu)^{2} / 2 \sigma^{2}} d x
\end{aligned}
$$

Substituting $\alpha_{C}^{e}$ into $\pi_{C s}^{e}\left(\alpha_{C}^{e}, T_{C}^{e}\right)$, we obtain the optimal profit of the supplier as follows:

$$
\begin{aligned}
& \pi_{C s}^{e *}\left(T_{C}^{e}\right)=\left(\sum_{i=1}^{n} \alpha_{C i}^{w} \int_{0}^{+\infty} x \frac{1}{\sqrt{2 \pi \sigma^{2}}} e^{-(x-\mu)^{2} / 2 \sigma^{2}} d x+\frac{K_{r}}{T_{C}^{w *}}+\sum_{i=1}^{n} \frac{T_{C}^{w *}}{2}\left(h_{i}+\alpha_{C i}^{w} \theta\right) \int_{0}^{+\infty} x \frac{1}{\sqrt{2 \pi \sigma^{2}}} e^{-(x-\mu)^{2} / 2 \sigma^{2}} d x\right. \\
& \left.-\frac{K_{r}}{T_{C}^{e}}-\sum_{i=1}^{n} \frac{h_{i} \int_{0}^{+\infty} x \frac{1}{\sqrt{2 \pi \sigma^{2}}} e^{-(x-\mu)^{2} / 2 \sigma^{2}} d x T_{C}^{e}}{2}\right) /\left(1+\frac{\theta T_{C}^{e}}{2}\right)-\frac{K_{s}}{T_{C}^{e}}-\sum_{i=1}^{n} c \int_{0}^{+\infty} x \frac{1}{\sqrt{2 \pi \sigma^{2}}} e^{-(x-\mu)^{2} / 2 \sigma^{2}} d x
\end{aligned}
$$

Taking the first derivative of Eq. (39) with respect to ordering cycle $T_{C}^{e}$, we obtain the following equation:

$$
\begin{gathered}
\frac{d \pi_{C s}^{e *}\left(T_{C}^{e}\right)}{d T_{C}^{e}}=\frac{-C\left(T_{C}^{e}\right)^{2}+\left(K_{s}+K_{r}\right) \theta T_{C}^{e}+K_{s}+K_{r}}{\left(1+\frac{\theta T_{C}^{e}}{2}\right)^{2}\left(T_{C}^{e}\right)^{2}} \\
\text { where } \quad C=\sum_{i=1}^{n} \frac{h_{i} \int_{0}^{+\infty} x \frac{1}{\sqrt{2 \pi \sigma^{2}}} e^{-(x-\mu)^{2} / 2 \sigma^{2}} d x}{2}+\frac{\theta}{2}\left(\sum_{i=1}^{n} \alpha_{C i}^{w} \int_{0}^{+\infty} x \frac{1}{\sqrt{2 \pi \sigma^{2}}} e^{-(x-\mu)^{2} / 2 \sigma^{2}} d x+\frac{K_{r}}{T_{C}^{e *}} .\right. \\
\left.+\sum_{i=1}^{n} \frac{T_{C}^{e^{*}}}{2}\left(h_{i}+\alpha_{C i}^{w} \theta\right) \int_{0}^{+\infty} x \frac{1}{\sqrt{2 \pi \sigma^{2}}} e^{-(x-\mu)^{2} / 2 \sigma^{2}} d x\right)-\frac{K_{s} \theta^{2}}{4}
\end{gathered}
$$

Solving $\frac{d \pi_{C s}^{e *}\left(T_{C}^{e}\right)}{d T_{C}^{e}}=0$, we obtain the following ordering cycle: 


$$
T_{C}^{c w *}=\frac{\left(K_{s}+K_{r}\right) \theta+\sqrt{\left(K_{s}+K_{r}\right)^{2} \theta^{2}+4 C\left(K_{s}+K_{r}\right)}}{2 C} .
$$

Due to the analytical solutions being difficult to analyze, we make the simulation with random demand. The demand follows the normal distribution $D \sim\left(\mu, \sigma^{2}\right)$. Here, we choose five cases $D \sim(100,15), D \sim(100,25), D \sim(100,45)$, $D \sim(120,25)$, and $D \sim(140,25)$ as the examples (see Figure 2 and Figure 3$)$ to illustrate.

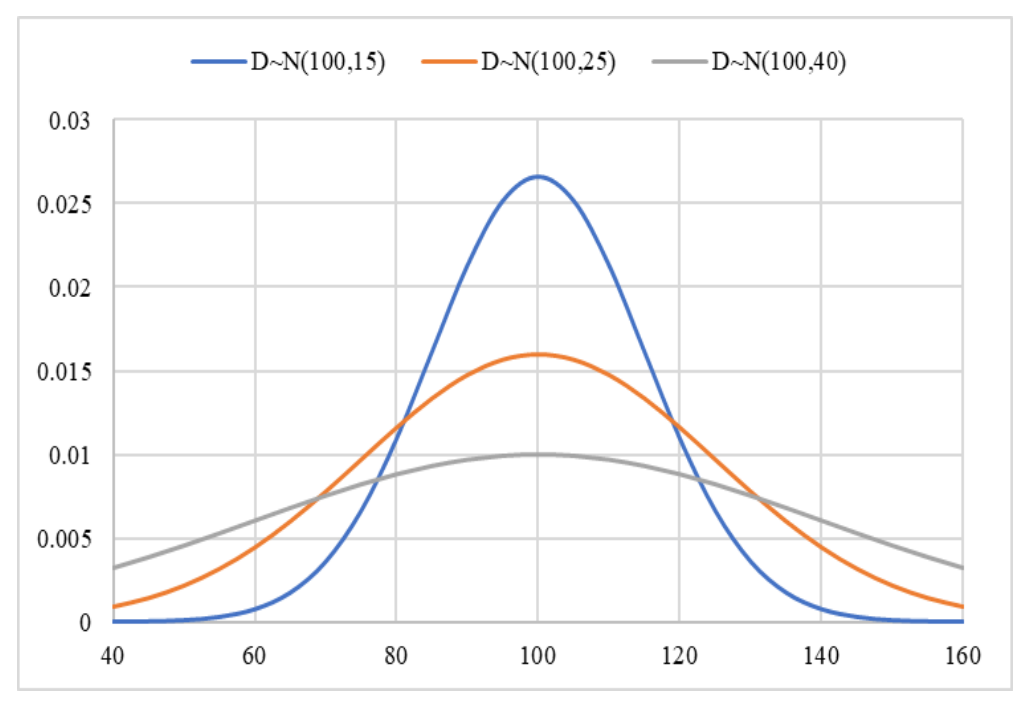

Figure 2 Normal distribution of demand with different variance

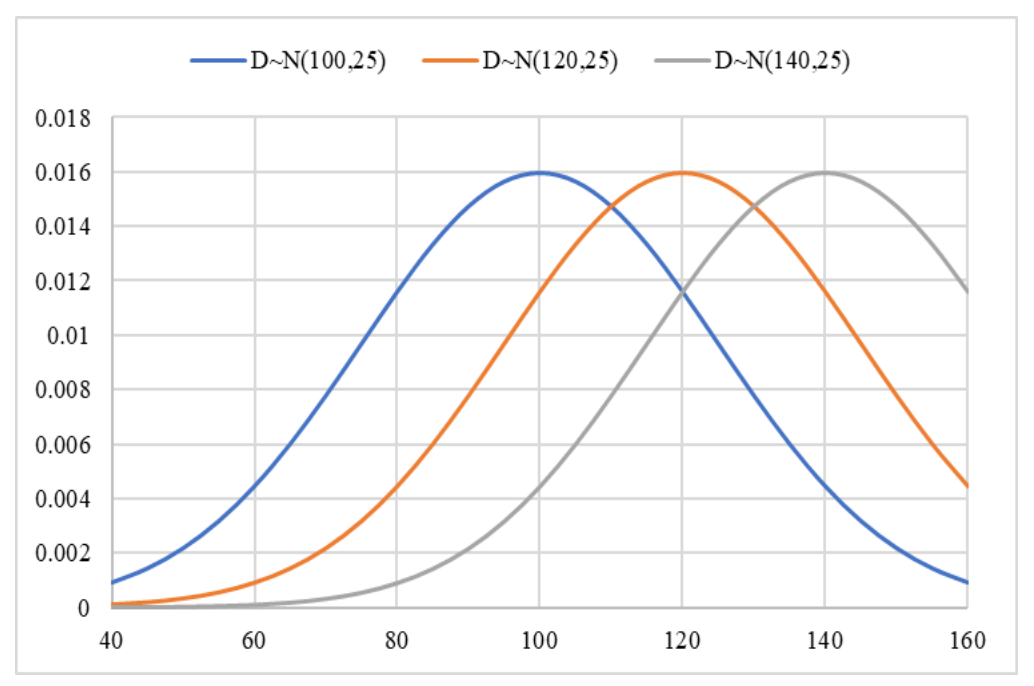

Figure 3 Normal distribution of demand with different mean

We assume the FPSC consists of one supplier and four retailers. To better 
illustrate, instead of using dummy numbers, we study a FPSC modified from the dataset of four supermarkets. We set the deterioration rate as $\theta=0.02$, the supplier’s fixed ordering cost as $K_{s}=¥ 100$ (CNY) per order, the retailer’s fixed ordering cost as $K_{r}=¥ 60$ per order, and the supplier’s procurement (or production) cost as $c=¥ 1.5$ per unit. The different parameters of retailer $i$ are summarized in Table 13.

Table 13 Parameters of retailer $i$

\begin{tabular}{ccccc}
\hline Retailer $i$ & 1 & 2 & 3 & 4 \\
\hline$h_{i}(\mathrm{CNY})$ & 0.8 & 0.5 & 0.7 & 0.9 \\
$p_{i}(\mathrm{CNY})$ & 5.0 & 4.8 & 4.5 & 5.2 \\
\hline
\end{tabular}

(1) Case 1: The demand follows the normal distribution $D \sim(100,15)$.

Using the parameters in Table 13, we apply them to the previously analyzed scenarios. Next, we analyze how the supplier's selling price and the retailers' ordering cycles affect the profits of both the supplier and the retailers when the demand follows the normal distribution $D \sim(100,15)$.

Table 14 Profits of the supplier and the retailers under independent procurement

\begin{tabular}{cccccc}
\hline \multirow{2}{*}{ Demand } & \multicolumn{5}{c}{ Profit (CNY) } \\
\cline { 2 - 6 } & Supplier & Retailer 1 & Retailer 2 & Retailer 3 & Retailer 4 \\
\hline 40 & 272.94 & 71.79 & 167.16 & 74.48 & 126.98 \\
60 & 309.17 & 90.42 & 186.55 & 89.29 & 148.21 \\
80 & 345.59 & 109.47 & 206.06 & 104.40 & 169.74 \\
90 & 382.17 & 128.88 & 225.69 & 119.74 & 191.52 \\
100 & 418.90 & 148.58 & 245.42 & 135.29 & 213.51 \\
110 & 455.76 & 168.54 & 265.25 & 151.02 & 235.71 \\
120 & 492.73 & 188.72 & 285.17 & 166.92 & 258.08 \\
140 & 529.80 & 209.10 & 305.17 & 182.96 & 280.61 \\
160 & 566.96 & 229.66 & 325.25 & 199.14 & 303.28 \\
\hline
\end{tabular}


The results in Table 14 show that the profits of the supplier and retailers increase as demand increases when the demand follows normal distribution $D \sim(100,15)$. The changing trend is similar with the case where the demand is deterministic.

Table 15 The supplier's selling price and the retailers' ordering cycles with different

\begin{tabular}{ccccc}
\multicolumn{3}{c}{ deterioration rates } \\
\hline$\theta$ & \multicolumn{2}{c}{ Independent procurement } & \multicolumn{2}{c}{ Joint procurement } \\
\cline { 2 - 5 } & $\alpha_{D i}^{c w^{*}}(\mathrm{CNY})$ & $T_{D i}^{c w^{*}}$ & $\alpha_{C}^{c w^{*}}(\mathrm{CNY})$ & $T_{C}^{c w^{*}}$ \\
\hline 0.01 & 2.4747 & 1.4947 & 2.6969 & 1.0261 \\
0.02 & 2.4691 & 1.4687 & 2.6947 & 1.0091 \\
0.03 & 2.4635 & 1.4441 & 2.6924 & 0.9929 \\
0.04 & 2.4581 & 1.4208 & 2.6902 & 0.9775 \\
\hline
\end{tabular}

When comparing independent procurement with joint procurement, it can be noted that under joint procurement the supplier's selling price is higher and the retailer's ordering cycle is shorter.

(2) Case 2: The demand follows the normal distribution $D \sim(100,25)$.

Using the parameters in Table 13, we apply them to the previously analyzed scenarios. Next, we analyze how the supplier's selling price and the retailers' ordering cycles affect the profits of both the supplier and the retailers when the demand follows the normal distribution $D \sim(100,25)$.

Table 16 Profits of the supplier and the retailers under independent procurement

\begin{tabular}{cccccc}
\hline \multirow{2}{*}{ Demand } & \multicolumn{5}{c}{ Profit (CNY) } \\
\cline { 2 - 6 } & Supplier & Retailer 1 & Retailer 2 & Retailer 3 & Retailer 4 \\
\hline 60 & 309.17 & 90.42 & 186.55 & 89.29 & 148.21 \\
70 & 327.35 & 99.90 & 196.29 & 96.81 & 158.94 \\
80 & 345.59 & 109.47 & 206.06 & 104.40 & 169.74 \\
90 & 382.17 & 128.88 & 225.69 & 119.74 & 191.52
\end{tabular}




\begin{tabular}{llllll}
\hline 100 & 418.90 & 148.58 & 245.42 & 135.29 & 213.51 \\
110 & 455.76 & 168.54 & 265.25 & 151.02 & 235.71 \\
120 & 492.73 & 188.72 & 285.17 & 166.92 & 258.08 \\
130 & 511.25 & 198.89 & 295.16 & 174.93 & 269.32 \\
140 & 529.80 & 209.10 & 305.17 & 182.96 & 280.61 \\
\hline
\end{tabular}

The results in Table 16 indicate that the profits of the supplier and retailers increase as demand increases when the demand follows the normal distribution $D \sim(100,25)$. The changing trend is similar with the case where the demand is deterministic.

Table 17 The supplier's selling price and the retailers' ordering cycles with different

\begin{tabular}{ccccc} 
& \multicolumn{3}{c}{ deterioration rates } \\
\hline$\theta$ & \multicolumn{2}{c}{ Independent procurement } & \multicolumn{2}{c}{ Joint procurement } \\
\cline { 2 - 5 } & $\alpha_{D i}^{c w^{*}}(\mathrm{CNY})$ & $T_{D i}^{c w^{*}}$ & $\alpha_{C}^{c w^{*}}(\mathrm{CNY})$ & $T_{C}^{c w^{*}}$ \\
\hline 0.01 & 2.4892 & 1.4259 & 2.7015 & 0.9789 \\
0.02 & 2.4839 & 1.4011 & 2.6993 & 0.9625 \\
0.03 & 2.4785 & 1.3776 & 2.6972 & 0.9471 \\
0.04 & 2.4733 & 1.3553 & 2.6951 & 0.9324 \\
\hline
\end{tabular}

When comparing independent procurement with joint procurement, it can be noted that under joint procurement the supplier's selling price is higher and the retailer's ordering cycle is shorter.

(3) Case 3: The demand follows the normal distribution $D \sim(100,40)$.

Using the parameters in Table 13, we apply them to the previously analyzed scenarios. Next, we analyze how the supplier's selling price and the retailers' ordering cycles affect the profits of both the supplier and the retailers when the demand follows the normal distribution $D \sim(100,40)$.

Table 18 Profits of the supplier and the retailers under independent procurement 


\begin{tabular}{cccccc}
\hline \multirow{2}{*}{ Demand } & \multicolumn{5}{c}{ Profit (CNY) } \\
\cline { 2 - 6 } & Supplier & Retailer 1 & Retailer 2 & Retailer 3 & Retailer 4 \\
\hline 80 & 345.59 & 109.47 & 206.06 & 104.40 & 169.74 \\
85 & 363.86 & 119.13 & 215.86 & 112.04 & 180.60 \\
90 & 382.17 & 128.88 & 225.69 & 119.74 & 191.52 \\
95 & 400.52 & 138.69 & 235.54 & 127.49 & 202.49 \\
100 & 418.90 & 148.58 & 245.42 & 135.29 & 213.51 \\
105 & 437.31 & 158.53 & 255.32 & 143.14 & 224.59 \\
110 & 455.76 & 168.54 & 265.25 & 151.02 & 235.71 \\
115 & 474.23 & 178.60 & 275.20 & 158.95 & 246.87 \\
120 & 492.73 & 188.72 & 285.17 & 166.92 & 258.08 \\
\hline
\end{tabular}

The results in Table 18 indicate that the profits of the supplier and retailers increase as demand increases when the demand follows the normal distribution $D \sim(100,40)$. The changing trend is similar with the case where the demand is deterministic.

Table 19 The supplier's selling price and the retailers' ordering cycles with different deterioration rates

\begin{tabular}{ccccc}
\hline \multirow{2}{*}{$\theta$} & \multicolumn{2}{c}{ Independent procurement } & \multicolumn{2}{c}{ Joint procurement } \\
\cline { 2 - 5 } & $\alpha_{D i}^{c w^{*}}(\mathrm{CNY})$ & $T_{D i}^{c w^{*}}$ & $\alpha_{C}^{c w^{*}}(\mathrm{CNY})$ & $T_{C}^{c w^{*}}$ \\
\hline 0.01 & 2.5019 & 1.3658 & 2.7055 & 0.9376 \\
0.02 & 2.4968 & 1.3420 & 2.7034 & 0.9219 \\
0.03 & 2.4917 & 1.3195 & 2.7014 & 0.9070 \\
0.04 & 2.4867 & 1.2981 & 2.6408 & 0.6230 \\
\hline
\end{tabular}

When comparing independent procurement with joint procurement, it can be noted that under joint procurement the supplier's selling price is higher and the retailer's ordering cycle is shorter.

(4) Case 4: The demand follows the normal distribution $D \sim(120,25)$. 
Using the parameters in Table 13, we apply them to the previously analyzed scenarios. Next, we analyze how the supplier's selling price and the retailers' ordering cycles affect the profits of both the supplier and the retailers when the demand follows the normal distribution $D \sim(120,25)$.

Table 20 Profits of the supplier and the retailers under independent procurement

\begin{tabular}{cccccc}
\hline \multirow{2}{*}{ Demand } & \multicolumn{5}{c}{ Profit (CNY) } \\
\cline { 2 - 6 } & Supplier & Retailer 1 & Retailer 2 & Retailer 3 & Retailer 4 \\
\hline 80 & 345.59 & 109.47 & 206.06 & 104.40 & 169.74 \\
90 & 382.17 & 128.88 & 225.69 & 119.74 & 191.52 \\
100 & 418.90 & 148.58 & 245.42 & 135.29 & 213.51 \\
110 & 455.76 & 168.54 & 265.25 & 151.02 & 235.71 \\
120 & 492.73 & 188.72 & 285.17 & 166.92 & 258.08 \\
130 & 511.25 & 198.89 & 295.16 & 174.93 & 269.32 \\
140 & 529.80 & 209.10 & 305.17 & 182.96 & 280.61 \\
150 & 548.37 & 219.36 & 315.20 & 191.04 & 291.92 \\
160 & 566.96 & 229.66 & 325.25 & 199.14 & 303.28 \\
\hline
\end{tabular}

The results in Table 20 indicate that the profits of the supplier and retailers increase as demand increases when the demand follows the normal distribution $D \sim(120,25)$. The changing trend is similar with the case where the demand is deterministic.

Table 21 The supplier's selling price and the retailers' ordering cycles with different

\begin{tabular}{ccccc}
\multicolumn{3}{c}{ deterioration rates } \\
\hline$\theta$ & \multicolumn{2}{c}{ Independent procurement } & \multicolumn{2}{c}{ Joint procurement } \\
\cline { 2 - 5 } & $\alpha_{D i}^{c w^{*}}(\mathrm{CNY})$ & $T_{D i}^{c w^{*}}$ & $\alpha_{C}^{c w^{*}}(\mathrm{CNY})$ & $T_{C}^{c w^{*}}$ \\
\hline \multirow{2}{*}{0.01} & 2.5133 & 1.3127 & 2.7090 & 0.9011 \\
0.02 & 2.5083 & 1.2898 & 2.7071 & 0.8860 \\
0.03 & 2.5034 & 1.2682 & 2.7051 & 0.8717
\end{tabular}


0.04

2.4986

1.2476

2.7032

0.8581

When comparing independent procurement with joint procurement, it can be noted that under joint procurement the supplier's selling price is higher and the retailer's ordering cycle is shorter.

(5) Case 5: The demand follows the normal distribution $D \sim(140,25)$.

Using the parameters in Table 13, we apply them to the previously analyzed scenarios. Next, we analyze how the supplier's selling price and the retailers' ordering cycles affect the profits of both the supplier and the retailers when the demand follows the normal distribution $D \sim(140,25)$.

Table 22 Profits of the supplier and the retailers under independent procurement

\begin{tabular}{cccccc}
\hline \multirow{2}{*}{ Demand } & \multicolumn{5}{c}{ Profit (CNY) } \\
\cline { 2 - 6 } & Supplier & Retailer 1 & Retailer 2 & Retailer 3 & Retailer 4 \\
\hline 100 & 418.90 & 148.58 & 245.42 & 135.29 & 213.51 \\
110 & 455.76 & 168.54 & 265.25 & 151.02 & 235.71 \\
120 & 492.73 & 188.72 & 285.17 & 166.92 & 258.08 \\
130 & 511.25 & 198.89 & 295.16 & 174.93 & 269.32 \\
140 & 529.80 & 209.10 & 305.17 & 182.96 & 280.61 \\
150 & 548.37 & 219.36 & 315.20 & 191.04 & 291.92 \\
160 & 566.96 & 229.66 & 325.25 & 199.14 & 303.28 \\
170 & 585.57 & 239.99 & 335.32 & 207.27 & 314.66 \\
180 & 604.20 & 250.37 & 345.41 & 215.43 & 326.07 \\
\hline
\end{tabular}

The results in Table 22 indicate that the profits of supplier and retailers increase as demand increases when the demand follows the normal distribution $D \sim(140,25)$. The changing trend is similar with the case where the demand is deterministic.

Table 23 The supplier's selling price and the retailers' ordering cycles with different 
deterioration rates

\begin{tabular}{ccccc}
\hline \multirow{2}{*}{$\theta$} & \multicolumn{2}{c}{ Independent procurement } & \multicolumn{2}{c}{ Joint procurement } \\
\cline { 2 - 5 } & $\alpha_{D i}^{c{ }^{* *}}(\mathrm{CNY})$ & $T_{D i}^{c w^{*}}$ & $\alpha_{C}^{c w *}(\mathrm{CNY})$ & $T_{C}^{c w^{*}}$ \\
\hline 0.01 & 2.5234 & 1.2653 & 2.7122 & 0.8686 \\
0.02 & 2.5186 & 1.2433 & 2.7103 & 0.8540 \\
0.03 & 2.5139 & 1.2224 & 2.7085 & 0.8401 \\
0.04 & 2.5092 & 1.2025 & 2.7066 & 0.8270 \\
\hline
\end{tabular}

When comparing independent procurement with joint procurement, it can be noted that under joint procurement the supplier's selling price is higher and the retailer's ordering cycle is shorter.

From the above cases, we can see that the profits of the supplier and the retailers are positively related to the demands of the fresh produce. The supplier's selling price under joint procurement is higher and the retailer's ordering cycle is shorter when comparing with the case of independent procurement. All the trends under the stochastic demand are similar to the deterministic case.

\section{Conclusions}

The BRI is a major international economic strategy and is an economic framework developed to increase the connectivity between China and the BRI partner countries. This initiative brings many opportunities for FPSC industries. In this paper, we examined an FPSC consisting of one supplier and multiple retailers in countries along the BRI. We are particularly interested in FPSC coordination through a quantity discount contract when the deterioration rate is considered. Two cases are considered in this study: independent procurement and joint procurement. In each case, we determine the optimal selling price for the supplier and the optimal ordering cycle. In addition, the optimal profit allocation for each retailer is assessed.

The results suggest that quantity discount contracts guarantee a win-win result between the supplier and the retailers; that is, the profit of each party under joint 
procurement is greater than that in the case of independent procurement, as explained by the following points:

- In negotiating the contract, when the change in the supplier's selling price is within a certain range, the supplier and the retailers can gain more profit than in the case without a contract.

- If the profit allocation satisfies the effectiveness conditions, then the retailers will have enough motivation to form a grand coalition. Notably, the profit of each retailer can be ensured when the number of retailers in the coalition is within a certain range.

- The total profit of the FPSC is negatively correlated with the deterioration rate of products; therefore, to reduce loss in the supply chain, the optimal ordering cycle must be carefully considered.

From a theoretical perspective, this research is one of only a few papers to study an FPSC consisting of one supplier and multiple retailers and to account for both the deterioration rate and the supply chain coordination cost simultaneously. Furthermore, many studies examine supply chain coordination strategies without considering the impact of coalition size on the coordination cost. However, in our paper, we derive analytic results for a coalition size that guarantees a higher profit for both the retailers and the supplier and for how to rationally allocate the profit among them, enriching our understanding of FPSC operations and management. From a practical perspective, when two or more retailers procure one kind of product from one supplier and they can use joint procurement and a quantity discount contract, it is necessary to encourage retailers to form a grand coalition through negotiation. If the supplier's selling price is within the range where both the supplier and the retailers gain more profit than under independent procurement, then all parties can agree on a quantity discount contract. In addition, if the coordination cost is higher than the increased profit, then joint procurement could be outsourced to a third-party logistics company to minimize the operational cost.

There are several directions that warrant further research. In this paper, we 
assume that a product shortage is not allowed. A natural extension is to examine a setting in which the supply and demand are not equal. As the level of demand in this research is assumed to be constant, another avenue of research would be to examine a situation in which demand is stochastic. Finally, we will extend our model to consider how an FPSC may be coordinated through a quantity discount contract in an incomplete information environment.

\section{Acknowledgments}

This work is supported by the National Natural Science Foundation of China (71431004), the Shanghai Planning Office of Philosophy and Social Science (2018EGL010), the China Scholarship Council (201506740026), and the Fundamental Research Funds for the Central Universities.

\section{Appendix A.}

\section{A.1. The proof of Proposition 1}

For any given $T_{D i}^{c w}$, taking the first derivative of $\pi_{D r i}^{c w}\left(\alpha_{D i}^{c w}, T_{D i}^{c w}\right)$ with respect to the selling price that the supplier charges the retailer $\alpha_{D i}^{c w}$, we obtain $\frac{\partial \pi_{D r i}^{c w}\left(\alpha_{D i}^{c w}, T_{D i}^{c w}\right)}{\partial \alpha_{D i}^{c w}}=-D_{i}-\frac{T_{D i}^{c w}}{2} \theta D_{i}<0$. Therefore, $\pi_{D r i}^{c w}\left(\alpha_{D i}^{c w}, T_{D i}^{c w}\right) \quad$ is a decreasing function of $\quad \alpha_{D i}^{c w}$. When $\pi_{D r i}^{c w}\left(\alpha_{D i}^{c w^{*}}, T_{D i}^{c w^{*}}\right) \geq \pi_{D r i}^{c w}\left(\alpha_{\max }^{c w^{*}}, T_{D i}^{c w^{*}}\right)$, we obtain $\alpha_{D i}^{c w *} \leq \alpha_{\max }^{c w *}=\min _{i \in N} \alpha_{D i}^{c w^{*}}$. From Eq. (10), the constraint condition, we know that retailer $i$ can earn more profit than in the case without the contract.

When $\pi_{D s}^{c w}\left(\alpha_{D i}^{c w^{*}}, T_{D i}^{c w^{*}}\right) \geq \sum_{i=1}^{n}\left(\alpha_{D i}^{w} D_{i}-c D_{i}-\frac{K_{s}}{T_{D i}^{w *}}\right)$, that is, when the supplier can earn more profit than in the case without the contract, we obtain $\alpha_{D i}^{c w *} \geq \alpha_{\min }^{c w *}=\sum_{i=1}^{n}\left(\alpha_{D i}^{w} D_{i}-K_{s} \sqrt{\frac{\left(h_{i}+\alpha_{D i}^{w} \theta\right) D_{i}}{2 K_{r}}}+\frac{K_{s}}{T_{D i}^{c w *}}\right) / \sum_{i=1}^{n} D_{i}$. 
Thus, the existence of $\left[\alpha_{\min }^{c w^{*}}, \alpha_{\max }^{c w^{*}}\right]$ is verified. The proof of Proposition 1 is completed.

\section{A.2. The proof of Lemma 1}

For any subset $M \subset R \subseteq N-\{j\}$, from Eq. (18), we can obtain the following:

$$
\begin{aligned}
& \pi(M \mathrm{U}\{j\})-\pi(M)=\left(p_{j}-\alpha_{0}\right) D_{j}-\frac{2 K_{r}\left(h_{j}+\alpha_{C i}^{w} \theta\right) D_{j}}{\sqrt{2 K_{r} \sum_{i \in M \mathrm{U}\{j\}}\left(h_{i}+\alpha_{C i}^{w} \theta\right) D_{i}}+\sqrt{2 K_{r} \sum_{i=1}^{m}\left(h_{i}+\alpha_{C i}^{w} \theta\right) D_{i}}} \\
& \leq\left(p_{j}-\alpha_{0}\right) D_{j}-\frac{2 K_{r}\left(h_{j}+\alpha_{C i}^{w} \theta\right) D_{j}}{\sqrt{2 K_{r} \sum_{i \in R \mathrm{U}\{j\}}\left(h_{i}+\alpha_{C i}^{w} \theta\right) D_{i}}+\sqrt{2 K_{r} \sum_{i=1}^{r}\left(h_{i}+\alpha_{C i}^{w} \theta\right) D_{i}}} \\
& =\pi(R \mathrm{U}\{j\})-\pi(R)
\end{aligned}
$$

Therefore, $\left(N, \pi_{C r}^{w}(M)\right)$ is a concave game.

\section{A.3. The proof of Proposition 2}

We know that $\sqrt{\sum_{i=1}^{n}\left(h_{i}+\alpha_{C i}^{w} \theta\right) D_{i}} \leq \sum_{i=1}^{n} \sqrt{\left(h_{i}+\alpha_{D i}^{w} \theta\right) D_{i}} ;$ therefore, $T_{C}^{w *} \geq \sum_{i=1}^{n} T_{D i}^{w *}$. Then,

$\sum_{i=1}^{n}\left(p_{i}-\alpha_{C i}^{w}\right) D_{i}-\sqrt{2 K_{r} \sum_{i=1}^{n}\left(h_{i}+\alpha_{C i}^{w} \theta\right) D_{i}} \geq \sum_{i=1}^{n}\left(p_{i}-\alpha_{D i}^{w}\right) D_{i}-\sum_{i=1}^{n} \sqrt{2 K_{r}\left(h_{i}+\alpha_{D i}^{w} \theta\right) D_{i}} ;$ that is, $\pi_{C r}^{w}\left(\alpha_{C i}^{w}, T_{C}^{w *}\right) \geq \sum_{i=1}^{n} \pi_{D r i}^{w}\left(\alpha_{D i}^{w}, T_{D i}^{w *}\right)$. This means that the retailer under joint procurement can obtain more profit than under independent procurement.

Similarly, $\quad \sum_{i=1}^{n}\left(\alpha_{C i}^{w}-c\right) D_{i}-\frac{K_{s}}{T_{C}^{w *}}>\sum_{i=1}^{n}\left(\alpha_{D i}^{w}-c\right) D_{i}-\frac{K_{s}}{\sum_{i=1}^{n} T_{D i}^{w *}} \quad ; \quad$ that is, $\pi_{C s}^{w}\left(\alpha_{C i}^{w}, T_{C}^{w^{*}}\right) \geq \pi_{D s}^{w}\left(\alpha_{D i}^{w}, T_{D}^{w *}\right)$. Clearly, joint procurement can improve the supplier's profit. 


\section{A.4. The proof of Proposition 3}

In this situation, the profits of retailers are given as follows:

$$
\pi_{C r}^{c w}\left(\alpha_{C}^{c w *}, T_{C}^{c w^{*}}\right)=\sum_{i=1}^{n}\left(p_{i}-\alpha_{C}^{c w}\right) D_{i}-\sqrt{2 K_{r} \sum_{i=1}^{n}\left(h_{i}+\alpha_{C}^{c w} \theta\right) D_{i}} .
$$

For any given $T_{C}^{c w}$, taking the first derivative of $\pi_{C r}^{c w}\left(\alpha_{C}^{c w}, T_{C}^{c w}\right)$ with respect to procurement price $\alpha_{C}^{c w}$, we obtain the following:

$$
\frac{d \pi_{C r}^{c w}\left(\alpha_{C}^{c w}, T_{C}^{c w}\right)}{d \alpha_{C}^{c w}}=-D_{i}-\frac{\sum_{i=1}^{n} \theta D_{i}}{2 \sqrt{2 K_{r} \sum_{i=1}^{n}\left(h_{i}+\alpha_{C}^{c w} \theta\right) D_{i}}}<0 .
$$

Therefore, $\pi_{C r}^{c w}\left(\alpha_{C}^{c w}, T_{C}^{c w}\right)$ is a decreasing function of $\alpha_{C}^{c w}$. When $\pi_{C r}^{c w}\left(\alpha_{C}^{c w *}, T_{C}^{c w *}\right) \geq \pi_{C r}^{c w}\left(\alpha_{\max }^{c w *}, T_{C}^{c w *}\right)$, we obtain $\alpha_{C}^{c w *} \leq \alpha_{\max }^{c w *}=\min _{i \in N} \alpha_{C}^{c w *}$. From Eq. (10), the constraint condition, we know that retailer $i$ can earn more profit than in the case without a contract.

When $\pi_{C s}^{c w}\left(\alpha_{C}^{c w^{*}}, T_{C}^{c w^{*}}\right) \geq \sum_{i=1}^{n}\left(\alpha_{C i}^{w}-c\right) D_{i}-\frac{K_{s}}{T_{C}^{w^{*}}}$, that is, when the supplier can earn more profit than in the case without a contract, we obtain $\alpha_{C}^{c w^{*}} \geq \alpha_{\min }^{c w^{*}}=\left(\sum_{i=1}^{n} \alpha_{C i}^{w} D_{i}+\frac{K_{r}}{T_{C}^{w^{*}}}+\sum_{i=1}^{n} \frac{T_{C}^{w^{*}}}{2}\left(h_{i}+\alpha_{C i}^{w} \theta\right) D_{i}-\frac{K_{r}}{T_{C}^{c w^{*}}}-\sum_{i=1}^{n} \frac{h_{i} D_{i} T_{C}^{c w^{*}}}{2}\right) / \sum_{i=1}^{n} D_{i}\left(1+\frac{\theta T_{C}^{c w^{*}}}{2}\right)$.

For any feasible quantity discount contract $\left(\alpha_{C}^{c w^{*}}, T_{C}^{c w^{*}}\right)$, it is necessary for the coalition to reasonably assign a portion of the total profit to each retailer under joint procurement. Consequently, all retailers will have an incentive to stay in the grand coalition. In general, the optimal ordering cycle $T_{C}^{c w^{*}}$ is equal to $T_{C}^{w^{*}}\left(\alpha_{C}^{c w^{*}}\right)$ when $\alpha_{C}^{c w *} \in\left[\alpha_{\min }^{c w *}, \alpha_{\max }^{c w *}\right]$, where $T_{C}^{w *}\left(\alpha_{C}^{c w *}\right)=\sqrt{\frac{2 K_{r}}{\sum_{i=1}^{n}\left(h_{i}+\alpha_{C}^{c w *} \theta\right) D_{i}}}$. Therefore, we can obtain 
the optimal ordering cycle:

$$
T_{C}^{c w *}\left(\alpha_{C}^{c w *}\right)=\sqrt{\frac{2 K_{r}}{\sum_{i=1}^{n}\left(h_{i}+\alpha_{C}^{c w *} \theta\right) D_{i}}}
$$

Therefore, to make the profit allocation $x_{i}\left(\alpha_{C}^{c w^{*}}, T_{C}^{c w^{*}}\right)$ satisfy effectiveness, note

that

$$
\sum_{i=1}^{n} x_{i}\left(\alpha_{C}^{c w^{*}}, T_{C}^{c w^{*}}\right)=\pi_{C r}^{c w}(N)
$$

where $x_{i}\left(\alpha_{C}^{c w *}, T_{C}^{c w^{*}}\right)=\left(p_{i}-\alpha_{C}^{c w^{*}}\right) D_{i}-\left(h_{i}+\alpha_{C}^{c w^{*}} \theta\right) D_{i} T_{C}^{c w *}$, and we can obtain the optimal profit allocation:

$$
x_{i}\left(\alpha_{C}^{c w}\right)=\left(p_{i}-\alpha_{C}^{c w}\right) D_{i}-\left(h_{i}+\alpha_{C}^{c w} \theta\right) D_{i} \sqrt{\frac{2 K_{r}}{\sum_{i=1}^{n}\left(h_{i}+\alpha_{C}^{c w} \theta\right) D_{i}}}
$$

Thus, the proof of Proposition 3 is complete.

\section{A.5. The proof of Corollary 1}

From Eq. (19) and Eq. (A1), we know that the profit of the supplier is as follows:

$$
\pi_{C s}^{c w}\left(\alpha_{C}^{c w}, T_{C}^{c w}\right)=\sum_{i=1}^{n}\left(\alpha_{C}^{c w}-c\right) D_{i}-K_{s} \sqrt{\frac{\sum_{i=1}^{n}\left(h_{i}+\alpha_{C}^{c w}\right) D_{i}}{2 K_{r}}}
$$

Taking the first derivative of Eq. (A3) with respect to $\theta$, we obtain $\frac{d \pi_{C s}^{c w}}{d \theta}=-K_{s} \sum_{i=1}^{n} \alpha_{C}^{c w} D_{i} / 2 \sqrt{\frac{\sum_{i=1}^{n}\left(h_{i}+\alpha_{C}^{c w} \theta\right) D_{i}}{2 K_{r}}}<0$. The profit of the supplier is negatively correlated with the deterioration rate. Taking the first derivative of Eq. (A2) with respect to $\theta$, we obtain $\frac{d x_{i}}{d \theta}=-\alpha_{C}^{c w} D_{i} T_{C}^{c w *}<0$. The profit of retailer $i$ is negatively correlated with the deterioration rate. Taking the first derivative of Eq.

(A1) with respect to $\theta$, we obtain $\frac{d T_{C}^{c w}}{d \theta}=-\sqrt{2 K_{r} \sum_{i=1}^{n} \alpha_{C}^{c w} D_{i}}<0$. The ordering cycle 
is negatively correlated with the deterioration rate. However, $\alpha_{C}^{c w *}$ must be in the range of $\left[\alpha_{\min }^{c w^{*}}, \alpha_{\max }^{c w^{*}}\right]$. Thus, we obtain Corollary 1.

\section{A.6. The proof of Proposition 4}

When the coordination cost is considered, the profit of fresh produce retailers is given

follows:

$$
\pi_{C r}^{e w}\left(\alpha_{C}^{e w *}, T_{C}^{e w *}\right)=\sum_{i=1}^{n}\left(p_{i}-\alpha_{C}^{e w}\right) D_{i}-\sqrt{2\left(K_{r}+k n+b\right) \sum_{i=1}^{n}\left(h_{i}+\alpha_{C}^{e w} \theta\right) D_{i}} .
$$

For any given $T_{C}^{e w}$, taking the first derivative of $\pi_{C}^{e w}\left(\alpha_{C}^{e w}, T_{C}^{e w}\right)$ with respect to the selling price that the supplier charges the retailer $\alpha_{C}^{e w}$, we derive the following:

$$
\frac{\partial \pi_{C}^{e w}\left(\alpha_{C}^{e w}, T_{C}^{e w}\right)}{\partial \alpha_{C}^{e w}}=-\sum_{i=1}^{n} D_{i}-\sum_{i=1}^{n}\left(\theta D_{i}\right) /\left(2 \sqrt{2\left(K_{r}+k n+b\right) \sum_{i=1}^{n}\left(h_{i}+\alpha_{C}^{e w} \theta\right) D_{i}}\right)<0
$$

Therefore, $\pi_{C}^{e w}\left(\alpha_{C}^{e w}, T_{C}^{e w}\right)$ is a decreasing function of $\alpha_{C}^{e w}$.

When $\pi_{C r}^{e w}\left(\alpha_{C}^{e w *}, T_{C}^{e w *}\right) \geq \pi_{C r}^{e w}\left(\alpha_{m a x}^{e w *}, T_{C}^{e w *}\right)$, we obtain $\alpha_{C}^{e w *} \leq \alpha_{\max }^{e w *}$. From Eq. (10), the constraint condition, we know that retailer $i$ can earn more profit than in the case without a contract.

When $\pi_{C s}^{e w}\left(\alpha_{C}^{e w^{*}}, T_{C}^{e w *}\right) \geq \sum_{i=1}^{n}\left(\alpha_{C}^{w}-c\right) D_{i}-\frac{K_{s}}{T_{C}^{e w^{*}}}$, that is, when the supplier can earn more profit than in the case without a contract, we obtain $\alpha_{C}^{e w *} \geq \alpha_{m i n}^{e w *}=\left(\sum_{i=1}^{n} \alpha_{C}^{w} D_{i}-\frac{K_{s}}{T_{D}^{e w *}}+\frac{K_{s}}{T_{C}^{e w *}}\right) / \sum_{i=1}^{n} D_{i}$

To make profit allocation $x_{i}\left(\alpha_{C}^{e w *}, T_{C}^{e w *}\right)$ satisfy effectiveness, note that $\sum_{i=1}^{m} x_{i}\left(\alpha_{C}^{e w *}, T_{C}^{e w *}\right)=\pi_{C r}^{e w}(M)$. From Eq. (27), we know that $T_{C}^{e w *}=\sqrt{\frac{2\left(K_{r}+k n+b\right)}{\sum_{i=1}^{n}\left(h_{i}+\alpha_{C}^{w} \theta\right) D_{i}}}$ Then, we can calculate the optimal profit allocation of the coalition of retailers as 
follows: $x_{i}^{*}\left(\alpha_{C}^{e w}\right)=\left(p_{i}-\alpha_{C}^{e w}\right) D_{i}-\left(h_{i}+\alpha_{C}^{e w} \theta\right) D_{i} \sqrt{\frac{2\left(K_{r}+k n+b\right)}{\sum_{i=1}^{n}\left(h_{i}+\alpha_{C}^{e w} \theta\right) D_{i}}}$.

Thus, the proof of Proposition 4 is complete.

\section{A.7. The proof of Proposition 5}

For $\forall i \in N$, note that

$$
x_{i}^{*}\left(\alpha_{C}^{e w}\right)=\left(p_{i}-\alpha_{C}^{w}\right) D_{i}-\left(h_{i}+\alpha_{C}^{w} \theta\right) D_{i} T_{C}^{e w *}
$$

Substituting Eq. (27) into Eq. (A4), we obtain the following:

$$
x_{i}^{*}\left(\alpha_{C}^{w}\right)=\left(p_{i}-\alpha_{C}^{w}\right) D_{i}-\left(h_{i}+\alpha_{C}^{w} \theta\right) D_{i} \sqrt{\frac{2\left(K_{r}+k m+b\right)}{\sum_{i=1}^{n}\left(h_{i}+\alpha_{C}^{w} \theta\right) D_{i}}}
$$

Let $x_{i}^{*} \geq \pi_{D r i}^{w}$; that is, the profit of each retailer is not less than that in the case without the quantity discount contract under joint procurement. Therefore, $\left(p_{i}-\alpha_{C}^{w}\right) D_{i}-\left(h_{i}+\alpha_{C}^{w} \theta\right) D_{i} \sqrt{\frac{2\left(K_{r}+k m+b\right)}{\sum_{i=1}^{n}\left(h_{i}+\alpha_{C}^{w} \theta\right) D_{i}}} \geq\left(p_{i}-\alpha_{C}^{w}\right) D_{i}-\sqrt{2 K_{r}\left(h_{i}+\alpha_{C}^{w} \theta\right) D_{i}}$. Then, we can obtain $0 \leq m \leq \frac{K_{r} \sum_{i=1}^{n}\left(h_{i}+\alpha_{C}^{w} \theta\right) D_{i}}{k\left(h_{i}+\alpha_{C}^{w} \theta\right) D_{i}}-\frac{K_{r}+b}{k}$.

Therefore, Proposition 5 is proven.

\section{References}

Akcay, Y., Natarajan, H. P., \& Xu, S. H. (2010). Joint dynamic pricing of multiple perishable products under consumer choice. Management Science, 56(8), 1345-1361.

Balcik, B., Beamon, B. M., Krejci, C. C., Muramatsu, K. M., \& Ramirez, M. (2010). Coordination in humanitarian relief chains: Practices, challenges and opportunities. International Journal of Production Economics, 126(1), 22-34.

Cai, X., Chen, J., Xiao, Y., Xu, X., \& Yu, G. (2013). Fresh-product supply chain management with logistics outsourcing. Omega, 41(4), 752-765. 
Cao, E., Wan, C., \& Lai, M. (2013). Coordination of a supply chain with one manufacturer and multiple competing retailers under simultaneous demand and cost disruptions. International Journal of Production Economics, 141(1), 425-433.

Chen, K. (2012). Procurement strategies and coordination mechanism of the supply chain with one manufacturer and multiple suppliers. International Journal of Production Economics, 138(1), $125-135$.

Chen, X., Pang, Z., \& Pan, L. (2014). Coordinating inventory control and pricing strategies for perishable products. Operations Research, 62(2), 284-300.

Dror, M., Hartman, B. C., \& Chang, W. (2012). The cost allocation issue in joint replenishment. International Journal of Production Economics, 135(1), 242-254.

Duan, Y., Luo, J., \& Huo, J. (2010). Buyer-vendor inventory coordination with quantity discount incentive for fixed lifetime product. International Journal of Production Economics, 128(1), $351-357$.

Gallego, G., \& Hu, M. (2014). Dynamic pricing of perishable assets under competition. Management Science, 60(5), 1241-1259.

Herbon, A., Levner, E., \& Cheng, T. C. E. (2014). Perishable inventory management with dynamic pricing using time-temperature indicators linked to automatic detecting devices. International Journal of Production Economics, 147, 605-613.

Hou, X., Haijema, R., \& Liu, D. (2017). Display, disposal, and order policies for fresh produce with a back storage at a wholesale market. Computers \& Industrial Engineering, 111, 18-28.

Jiang, Y., Chen, L., \& Fang, Y. (2018). Integrated Harvest and Distribution Scheduling with Time Windows of Perishable Agri-Products in One-Belt and One-Road Context. Sustainability, (10), 1-13.

Li, S., Zhang, J., \& Tang, W. (2015). Joint dynamic pricing and inventory control policy for a stochastic inventory system with perishable products. International Journal of Production Research, 53(10), 2937-2950.

Lim, Y. F., Wang, Y., \& Wu, Y. (2015). Consignment Contracts with Revenue Sharing for a Capacitated Retailer and Multiple Manufacturers. Manufacturing \& Service Operations Management, 17(4), 527-537.

Liu, X., Zhang, K., \& Chen, B. (2018). Analysis of logistics service supply chain for the One Belt and One Road initiative of China. Transportation Research Part E, 117(February), 23-39.

Mohebbi, S., \& Li, X. (2015). Coalitional Game Theory Approach to Modeling Suppliers' Collaboration in Supply Networks. International Journal of Production Economics, 169(2), 333-342.

Nie, X., Boyac1, T., Gümüss, M., Ray, S., \& Zhang, D. (2015). Joint procurement and demand-side bidding strategies under price volatility. Annals of Operations Research, 257(1), 121-165.

Noori-Daryan, M., Taleizadeh, A. A., \& Govindan, K. (2017). Joint replenishment and pricing 
decisions with different freight modes considerations for a supply chain under a composite incentive contract. Journal of the Operational Research Society, (1), 1-20.

Sainathan, A. (2013). Pricing and replenishment of competing perishable product variants under dynamic demand substitution. Production and Operations Management, 22(5), 1157-1181.

Shao, J., Krishnan, H., \& McCormick, S. T. (2011). Incentives for transshipment in a supply chain with decentralized retailers. Manufacturing \& Service Operations Management, 13(3), $361-372$.

Sheu, J. B., \& Kundu, T. (2018). Forecasting time-varying logistics distribution flows in the One Belt-One Road strategic context. Transportation Research Part E, 117, 5-22.

Taleizadeh, A. A., Mohammadi, B., Cárdenas-Barrón, L. E., \& Samimi, H. (2013). An EOQ model for perishable product with special sale and shortage. International Journal of Production Economics, 145(1), 318-338.

Taleizadeh, A. A., \& Noori-daryan, M. (2015). Pricing , manufacturing and inventory policies for raw material in a three-level supply chain. International Journal of Systems Science, 47(4), 919-931.

Taleizadeh, A. A., Stojkovska, I., \& Pentico, D. W. (2014). An Economic Order Quantity model with partial backordering and all-units discount. International Journal of Production Economics, 155, 172-184.

Taleizadeh, A. A., Stojkovska, I., \& Pentico, D. W. (2015). An economic order quantity model with partial backordering and incremental discount. Computers \& Industrial Engineering, 82, $21-32$.

Taleizadeh, A., Noori-daryan, M., \& Govindan, K. (2016). Pricing and ordering decisions of two competing supply chains with different composite policies: a Stackelberg game-theoretic approach. International Journal of Production Research, 54(9), 2807-2836.

Taleizadeh, A., Reza, V., \& Choi, T. (2017). Optimal pricing and alliance strategy in a retailer-led supply chain with the return policy: A game-theoretic analysis. Information Sciences, 420, 466-489.

Tat, R., Taleizadeh, A. A., \& Esmaeili, M. (2015). Developing economic order quantity model for non-instantaneous deteriorating items in vendor- managed inventory ( VMI ) system. International Journal of Systems Science, 46(7), 1257-1268.

Tavakoli, S., \& Taleizadeh, A. A. (2017). An EOQ model for decaying item with full advanced payment and conditional discount. Annals of Operations Research, 259(3), 1-22.

Wang, C., \& Chen, X. (2017). Option pricing and coordination in the fresh produce supply chain with portfolio contracts. Annals of Operations Research, 248(1), 471-491.

Wang, X., \& Li, D. (2012). A dynamic product quality evaluation based pricing model for perishable food supply chains. Omega, 40(6), 906-917.

Ye, Y., Ma, Z., \& Dai, Y. (2016). The price of anarchy in competitive reverse supply chains with 
quality-dependent price-only contracts. Transportation Research Part E, 89, 86-107.

Zeng, Q., Wang, G. W. Y., Qu, C., \& Li, K. X. (2018). Impact of the Carat Canal on the evolution of hub ports under China's Belt and Road initiative. Transportation Research Part E, 117, 96-107.

Zhang, J., Liu, G., Zhang, Q., \& Bai, Z. (2015). Coordinating a supply chain for deteriorating items with a revenue sharing and cooperative investment contract. Omega, 56, 37-49.

Zhang, W.-G., Fu, J., Li, H., \& Xu, W. (2012). Coordination of supply chain with a revenue-sharing contract under demand disruptions when retailers compete. International Journal of Production Economics, 138(1), 68-75.

Zheng Q., Ieromonachou P., Fan T., Z. L. (2017). Supply chain contracting coordination for fresh products with fresh-keeping effort. Industrial Management \& Data Systems, 117(3), 538-559. 